Article

\title{
Early Detection and Quantification of Verticillium Wilt in Olive Using Hyperspectral and Thermal Imagery over Large Areas
}

\author{
Rocío Calderón, Juan A. Navas-Cortés and Pablo J. Zarco-Tejada * \\ Instituto de Agricultura Sostenible (IAS), Consejo Superior de Investigaciones Científicas (CSIC), \\ Alameda del Obispo s/n, Córdoba 14004, Spain; E-Mails: rcalderon@ias.csic.es (R.C.); \\ j.navas@csic.es (J.A.N.-C.) \\ * Author to whom correspondence should be addressed; E-Mail: pablo.zarco@csic.es; \\ Tel.: +34-957-499-280 or +34-676-954-937; Fax: +34-957-499-252.
}

Academic Editors: Yoshio Inoue and Prasad S. Thenkabail

Received: 7 January 2015 / Accepted: 24 April 2015 / Published: 4 May 2015

\begin{abstract}
Automatic methods for an early detection of plant diseases (i.e., visible symptoms at early stages of disease development) using remote sensing are critical for precision crop protection. Verticillium wilt (VW) of olive caused by Verticillium dahliae can be controlled only if detected at early stages of development. Linear discriminant analysis (LDA) and support vector machine (SVM) classification methods were applied to classify $V$. dahliae severity using remote sensing at large scale. High-resolution thermal and hyperspectral imagery were acquired with a manned platform which flew a 3000-ha commercial olive area. LDA reached an overall accuracy of $59.0 \%$ and a $\kappa$ of 0.487 while SVM obtained a higher overall accuracy, $79.2 \%$ with a similar $\kappa, 0.495$. However, LDA better classified trees at initial and low severity levels, reaching accuracies of 71.4 and $75.0 \%$, respectively, in comparison with the $14.3 \%$ and $40.6 \%$ obtained by SVM. Normalized canopy temperature, chlorophyll fluorescence, structural, xanthophyll, chlorophyll, carotenoid and disease indices were found to be the best indicators for early and advanced stage infection by VW. These results demonstrate that the methods developed in other studies at orchard scale are valid for flights in large areas comprising several olive orchards differing in soil and crop management characteristics.
\end{abstract}

Keywords: Verticillium wilt; early detection; hyperspectral; thermal; support vector machine; linear discriminant analysis 


\section{Introduction}

Olive (Olea europaea L.) is one of the most important crops in the Mediterranean Basin, representing $95 \%$ of the world production. Spain is the leading olive-producing country with $25 \%$ of the world's acreage and nearly $39 \%$ of the production [1]. Verticillium wilt (VW), caused by the fungus Verticillium dahliae Kleb., is the main soil-borne disease threatening this crop worldwide [2]. In Spain, VW is of increasing concern for olive production because of its rapid spread and increasing severity associated with recent changes in cropping practices implemented to increase olive yields [2,3]. These changes include use of self-rooted planting stocks to establish high-tree-density, drip irrigation, reduced or no tillage and high inputs of fertilizers in newly cultivated soils or fertile soils [4] previously grown with susceptible crops to $V$. dahliae, such as cotton [3].

Currently, no control measure applied singly is fully effective for the management of VW of olive, however, an integrated disease management strategy is the best way to manage the disease, combining the use of preventive, pre-planting and post-planting control measures [5]. Post-planting control measures include: cultural practices (e.g., irrigation managing, weed control and tillage practice), soil solarization and organic or biological amendments. Post-planting VW control measures would be more efficient if VW-affected trees patches within fields are identified at early stages of disease development (i.e., visible symptoms) in order to mitigate the spread of the pathogen and successive infections to neighboring trees [6]. However, visual inspection of disease symptoms at early stages of development in the field is time-consuming and expensive [7]. Remote sensing for the detection of damage caused by soil-borne plant pathogens has proved to be the best-fit technology for optimization of integrated pest management. These methods are rapid and reliable, allowing real-time plant disease monitoring for disease control and management $[8,9]$.

$V$. dahliae infects the plant through the roots and colonizes its vascular system, blocking water flow and eventually inducing wilt symptoms [10]. This damage results in a significant reduction in leaf transpiration rate which finally leads to leaf chlorosis and defoliation, causing a change of spectral reflectance [11]. Chlorophyll content tends to decrease in infected plants, showing a higher reflectance in the visible (VIS) green $(550 \mathrm{~nm})$ and red-edge $(650-720 \mathrm{~nm})$ regions. Stressed plants also show a drop in canopy density and leaf area that leads to a decrease of spectral reflectance in the near-infrared (NIR) range (680-800 nm). In addition, the thermal-infrared (TIR) region $(8000-15,000 \mathrm{~nm})$ is highly suitable for the detection of $V$. dahliae infection due to the decrease in transpiration rate which induces stomata closure, reducing evaporative cooling and increasing canopy temperature. Considering these changes in the spectrum of infected plants, disease symptoms could be remotely detected in the VIS, red edge, NIR and TIR regions.

Recent work on VW in olive trees demonstrated the success of high-resolution thermal and hyperspectral imagery acquired with an unmanned aerial vehicle to early detect $V$. dahliae infection in two olive commercial orchards in southern of Spain [12]. Normalized canopy temperature (Tc-Ta), chlorophyll fluorescence and blue ratios $\mathrm{B} / \mathrm{BG} / \mathrm{BR}$ were found to be the best indicators of early stage infection by VW while the Photochemical Reflectance Index (PRI), structural, chlorophyll and carotenoid indices detected only moderate to severe $V$. dahliae infection. These results obtained at the canopy level using airborne imagery were confirmed by those obtained by Calderón et al. [13] at leaf level under controlled conditions. SPAD readings (as an indicator of leaf chlorophyll content), leaf 
chlorophyll fluorescence and normalized leaf temperature were demonstrated to be early VW indicators while the ethylene production and PRI detected only advanced stages of VW development.

Up to now, the remote sensing methods discussed above have only been used to detect VW successfully at local scales, in particular, in olive orchards of no more than 10 hectares using small unmanned aircraft. Under these small-scale conditions, unmanned aerial platforms obtain high resolution imagery in short flights of 10-40 min that avoid large ambient temperature variations, large changes in illumination levels or atmospheric differences during the flight. In addition, the methods were tested in olive orchards with homogeneous tree structural and crown shape characteristics as well as with a generally uniform background types, understory and soil types across the field. The collection of very high-resolution hyperspectral and thermal imagery over large areas is only possible using manned aircraft or high endurance unmanned aerial systems (UAS) flying over long periods to cover extensive areas at the optimum resolution (i.e., $30-50 \mathrm{~cm}$ pixel size) generating mosaics comprising several fields of very different structural and architectural characteristics (i.e., planting patterns, crown shapes and sizes, and background/soil types). Therefore, it is critical to assess methods to detect VW incidence and severity over large areas in order to design VW control strategies at large scale. In this way, the indices identified as indicators for the early and advanced VW detection at local scale [12] should be tested at larger scales to demonstrate their robustness and accuracy over orchards of varying types and conditions.

When acquiring hyperspectral imagery, large amounts of data are obtained and calculated from each single tree; therefore, the analysis is complex and different approaches can be used to obtain satisfactory results [9]. In this study, large hyperspectral $(50 \mathrm{~cm})$ and thermal $(62 \mathrm{~cm})$ mosaics were obtained (ca. 3000 hectares) comprising a total of 130 fields in order to test different methods for the successful detection among VW severity levels using two different supervised classification approaches: linear and non-linear classification methods. On the one hand, linear classification tries to find linear functions that separate the observations into the different classes. Several linear classification methods have been used to successfully classify remote sensing data for disease detection, such as linear discriminant analysis (LDA) [14], principal component analysis (PCA) [15] and logistic regression analysis (LRA) [16]. For the data analyzed in this study, we selected LDA rather than LRA because LDA is a more powerful and efficient analytic strategy when the assumptions of multivariate normality of the independent variables within each class are met, the dependent variable has more than two groups and not all classes have large sample size [17]. Moreover, LDA is superior to PCA in classifying remote sensing data because PCA changes the shape and location of the original data when transformed to a different space whereas LDA only tries to provide more class separability and draw a decision region between the given classes [18]. The classification criterion of LDA [19] is based on the pooled covariance matrix yielding a linear function and each observation is placed in the class from which it has the smallest generalized squared distance. On the other hand, when classes are not separable by linear boundary, non-linear classification methods are more appropriate. For disease detection from remote sensing data, artificial neural networks (NN) [20] and support vector machines (SVM) [21] have been the most used non-linear classification methods. SVM methods have been selected in this study because of the superior performance shown, particularly with respect to the classification of hyperspectral remote sensing data [22]. The advantages of SVM over NN [23] are: (i) the solution achieved by SVM is global and unique due to quadratic programming; (ii) computational complexity of SVM does not depend on the dimensionality of the input space so it is 
usually much quicker for large data sets; (iii) SVM is less prone to overfitting; (iv) SVM has few parameters to consider; and (v) has good generalization capability with few training samples. SVM is based on statistical learning theory [24] which aims determine a hyperplane that optimally separates two classes. The optimum hyperplane works in the manner that maximizes the margin between classes.

This study describes an automatic procedure to classify VW infection and severity in olive growing areas with a special focus on the early detection to design focalized VW control strategies at large scale. Because VW is related to several physiological modifications which are reflected in spectral changes, a method based on the combination of various vegetation indices calculated from high-resolution hyperspectral and thermal imagery was applied using LDA and SVM classification methods to fully exploit their combined information.

\section{Material and Methods}

\subsection{Study Site Description}

The study site is located in Écija (Seville province, southern Spain) (37 $\left.40^{\prime} 46^{\prime \prime} \mathrm{N}, 4^{\circ} 59^{\prime} 41^{\prime \prime W}\right)$ and consisted of a 3000-ha commercial olive area (Figure 1). Within this area, several olive orchards were selected differing in soil and crop management characteristics that are shown in Table 1 and Figure 1. All plots were drip-irrigated.
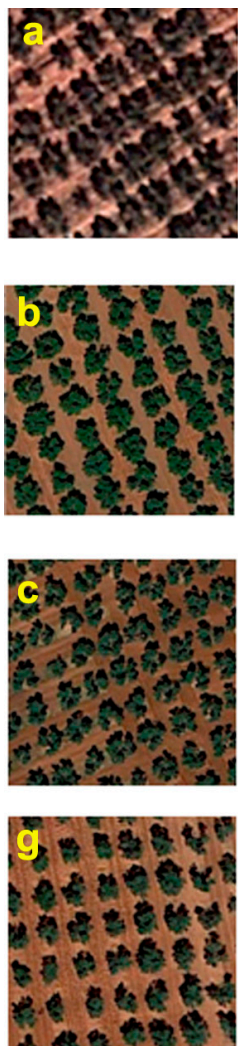
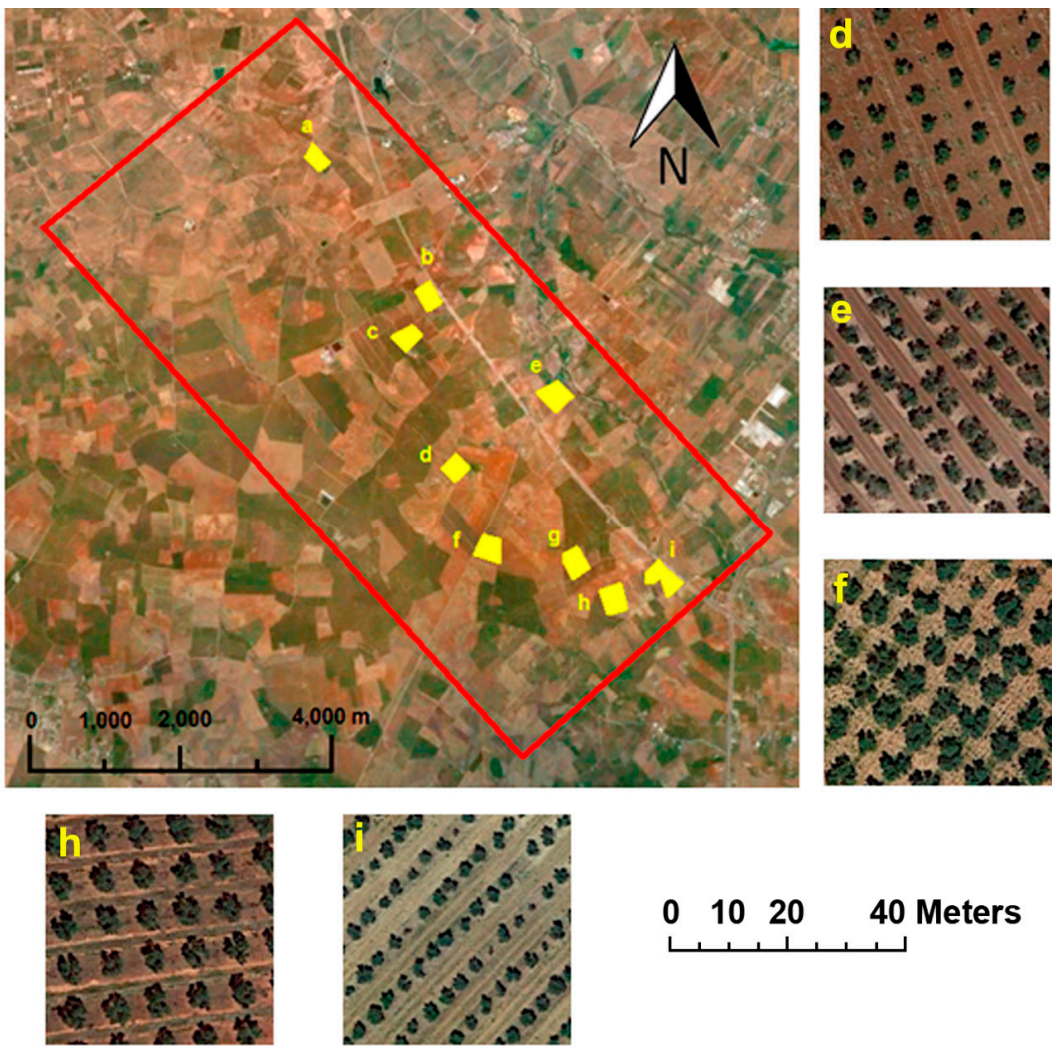

Figure 1. Overview of the olive area flown with the manned platform located in Écija (Seville province). Verticillium wilt severity was assessed in the plots which are shown in yellow. High-resolution detail of each individual olive plot assessed in this study was shown with lettering (a-i) in agreement with the plot lettering $(\mathbf{a}-\mathbf{i})$ in central image. Note differences in soil and crop management among plots. 
The climate of the area is Mediterranean characterized by warm and dry summers and cool and wet winters with an average annual rainfall of $550 \mathrm{~mm}$, concentrated from autumn to spring climate [25].

Table 1. Agronomic characteristics of olive plots assessed in this study.

\begin{tabular}{ccccc}
\hline Plot & Olive Cultivar & Plant Age (Years) & Plant Density (Trees per ha.) & Soil Management \\
\hline 1 & Picual & 30 & 204 & Non tillage \\
2 & Hojiblanca & 20 & 204 & Tillage \\
3 & Picual & 20 & 204 & Tillage \\
4 & Hojiblanca & 15 & 204 & Tillage \\
5 & Picual & 20 & 204 & Tillage \\
6 & Picual & 15 & 357 & Tillage \\
7 & Hojiblanca & 30 & 123 & Non tillage \\
8 & Picual & 20 & 204 & Tillage \\
9 & Picual & 30 & 204 & Non tillage \\
\hline
\end{tabular}

\subsection{Verticillium Wilt Assessment}

Incidence and severity of VW symptoms were assessed in the summer of 2013 in nine selected plots spatially distributed throughout the study site, collecting data for 5352 olive trees. Disease severity (DS) was assessed by visual inspection of every tree for foliar symptoms and assessment on a 0-4 rating scale according to the percentage of foliage with disease symptoms, where: $0=0 \%, 0.2$ and $0.5=$ initial symptoms, $1=1 \%-33 \%, 2=34 \%-66 \%, 3=67 \%-100 \%$, and $4=$ dead plant [12]. These VW severity levels were then regrouped in five VW severity classes: asymptomatic (DS $=0$ ), initial $(0.2 \leq \mathrm{DS} \leq 0.5)$, low $(1 \leq \mathrm{DS} \leq 1.5)$, moderate $(2 \leq \mathrm{DS} \leq 2.5)$ and severe $(3 \leq \mathrm{DS} \leq 4)$ symptoms (Figure 2). $V$. dahliae infection was confirmed by isolating six stem fragments sampled from each of four young symptomatic branches per symptomatic tree as previously described [6]. Identification of $V$. dahliae isolates was based on the morphology of conidiophores and microsclerotia and confirmed by molecular typing through PCR assay using primers DB19/DB22/espdef01 [26]. This method yielded a polymorphic amplicon of 523 or 539 bp specific to $V$. dahliae. PCR amplification and gel electrophoresis were conducted as previously described [26].

\subsection{Airborne Hyperspectral and Thermal Imagery Acquisition}

Imagery was acquired from the whole study site on 12 June 2013 using a hyperspectral sensor and a broad-band thermal camera on board a Cessna aircraft operated by the Laboratory for Research Methods in Quantitative Remote Sensing of the Consejo Superior de Investigaciones Científicas (QuantaLab, IAS-CSIC, Spain). Both cameras were flown at $500 \mathrm{~m}$ above ground level (AGL). Hyperspectral and thermal images were acquired between 10:30 and 12:00 GMT at $50 \mathrm{~cm}$ and $62 \mathrm{~cm}$ pixel resolution, respectively.

The hyperspectral sensor flown was the visible and near-infrared (VNIR) micro-hyperspectral imager (Micro-Hyperspec VNIR model, Headwall Photonics, MA, USA) configured in the spectral mode of 260 bands at $1.85 \mathrm{~nm} /$ pixel and 12-bit radiometric resolution. It yielded a $6.4 \mathrm{~nm}$ full-width at half-maximum (FWHM) with a 25-micron slit in the 400-885 $\mathrm{nm}$ region. Data acquisition and storage rate on board the manned platform was set to 50 fps (frames per second) with 18-ms integration time. 
The 8-mm optical focal length lens yielded an instantaneous field of view (IFOV) of $0.93 \mathrm{mrad}$ and an angular field of view (FOV) of $49.82^{\circ}$.
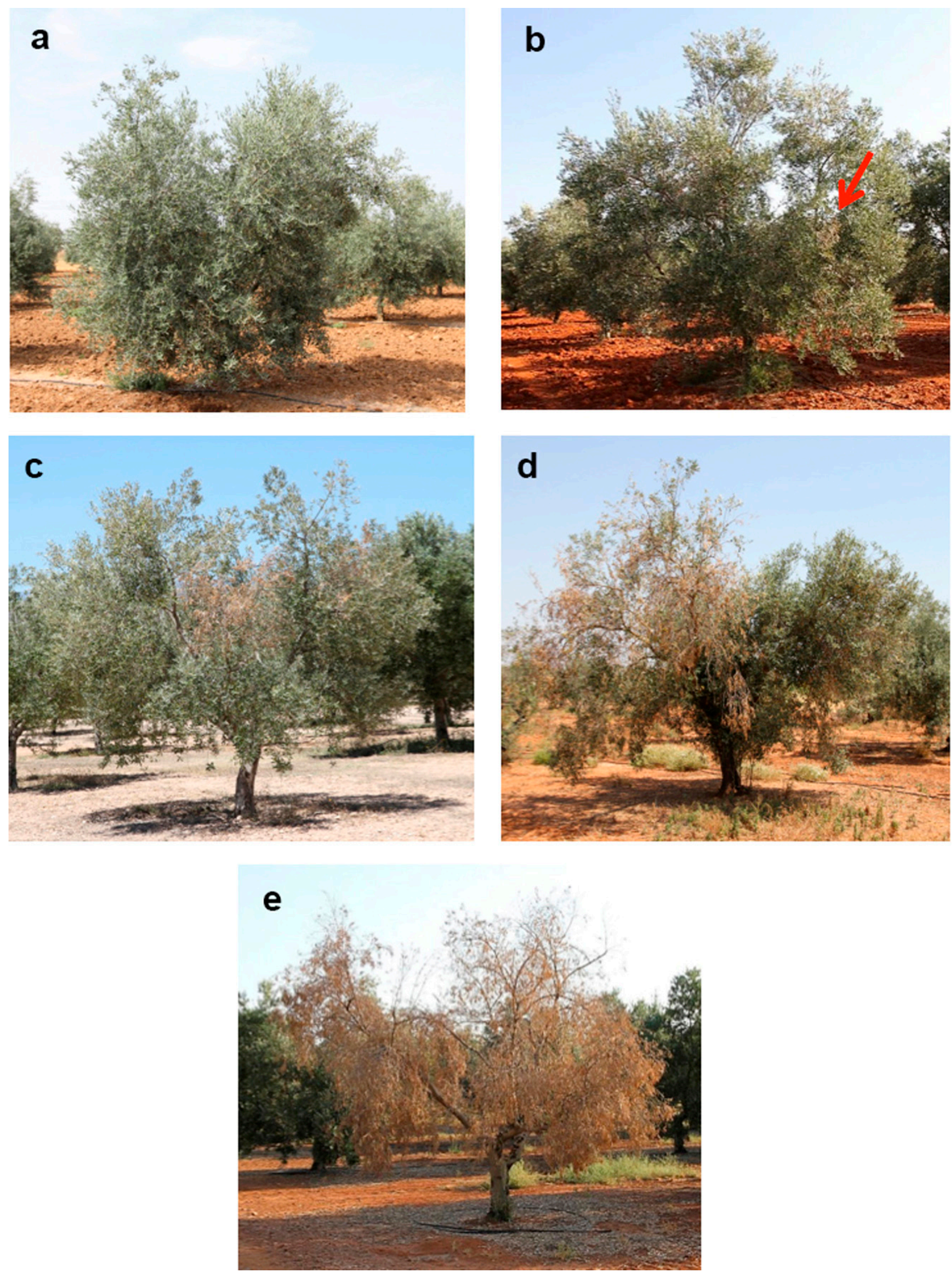

Figure 2. RGB images showing olive trees with the five different Verticillium wilt severity classes: (a) asymptomatic, (b) initial, (c) low, (d) moderate and (e) severe disease symptoms. 
Radiometric calibration and atmospheric correction methods were applied to the imagery to calculate the spectral reflectance, as described Zarco-Tejada et al. [27]. The hyperspectral images were radiometrically calibrated in the laboratory using derived coefficients with a uniform light source system (integrating sphere, CSTM-USS-2000C Uniform Source System, LabSphere, North Sutton, NH, USA) at four levels of illumination and six integration times. Radiance values were converted to reflectance using total incoming irradiance simulated with SMARTS model $[28,29]$ and aerosol optical depth measured at $550 \mathrm{~nm}$ with Micro-Tops II sunphotometer (Solar LIGHT Co., Philadelphia, PA, USA) at the study site at the time of the flight $[30,31]$. This model has been previously used in other studies to perform the atmospheric correction of hyperspectral imagery, such as in Zarco-Tejada et al. [27] and Calderón et al. [12].

Bidirectional reflectance effects are prominent for airborne sensors operating with wide FOV (e.g., in this study the FOV of hyperspectral sensor was $49.82^{\circ}$ ). Effects are most pronounced in the angular range higher than $\pm 30^{\circ}$ from nadir [32]. To minimize directional effects, the flight was conducted in the solar plane, trying to keep the assessed olive orchards as close as possible to the nadir within angular range $\pm 30^{\circ}$ from nadir. Hyperspectral reflectance from each training tree was acquired within a range in view angle between $-21.6^{\circ}$ and $+18.6^{\circ}$ from nadir. These data ensured that training trees were not affected by off-nadir pixels acquired on each single frame. Ranges in view angles between training trees from the same olive orchard were between $9.3^{\circ}$ and $31.4^{\circ}$ range. Moreover, due to the large along- and cross-track overlap achieved during the flight $(>70 \%)$, the resulting hyperspectral mosaic was not affected by pixels falling on the edge of the imagery.

Ortho-rectification of the hyperspectral imagery was conducted using PARGE (ReSe Applications Schläpfer, Wil, Switzerland). This was done using input data acquired with a miniaturized inertial measuring unit (IMU) (MTiG model, Xsens, The Netherlands) installed on-board and synchronized with the micro-hyperspectral imager. The mean radiance and reflectance spectra calculated from the 260 spectral bands obtained by the hyperspectral imager were used to calculate several narrow-band hyperspectral indices in agreement to the study conducted by Calderón et al. [12], where their ability to detect Verticillium wilt at early and/or advanced stages of disease development was demonstrated. The indices that contribute most to the model conducted in this study are shown in Table 2 with regard to: (i) tree crown structure; (ii) epoxidation state of the xanthophyll cycle; (iii) chlorophyll $a+b$ concentration; (iv) blue/green/red ratio indices; (v) carotenoid concentration; (vi) chlorophyll fluorescence and (vii) spectral disease indices.

Table 2. Overview of the vegetation indices that contribute most to the model conducted in this study and their formulations.

\begin{tabular}{llc}
\hline Vegetation Indices & Equation & Reference \\
\hline Structural indices & & \\
Normalized Difference Vegetation Index & NDVI $=\left(R_{800}-R_{670}\right) /\left(R_{800}+R_{670}\right)$ & {$[33]$} \\
Renormalized Difference Vegetation Index & $R D V I=\left(R_{800}-R_{670}\right) / \sqrt{\left(R_{800}+R_{670}\right)}$ & {$[34]$} \\
Enhanced Vegetation Index & $E V I=2.5 \cdot\left(R_{800}-R_{670}\right) /\left(R_{800}+6 \cdot R_{670}-7.5 \cdot R_{400}+1\right)$ & {$[35]$} \\
Optimized Soil-Adjusted Vegetation Index & OSAVI $=\left((1+0.16) \cdot\left(R_{800}-R_{670}\right) /\left(R_{800}+R_{670}+0.16\right)\right)$ & {$[36]$} \\
Triangular Vegetation Index & $T V I=0.5 \cdot\left[120 \cdot\left(R_{750}-R_{550}\right)-200 \cdot\left(R_{670}-R_{550}\right)\right]$ & {$[37]$} \\
Modified Triangular Vegetation Index & $M T V I=1.2 \cdot\left[1.2 \cdot\left(R_{800}-R_{550}\right)-2.5 \cdot\left(R_{670}-R_{550}\right)\right]$ & {$[38]$} \\
Modified Simple Ratio & $M S R=\frac{R_{800} / R_{670}-1}{\left(R_{800} / R_{670}\right)^{0.5}+1}$ & {$[39]$} \\
\hline
\end{tabular}


Table 2. Cont.

\begin{tabular}{|c|c|c|}
\hline Vegetation Indices & Equation & Reference \\
\hline \multicolumn{3}{|l|}{ Xanthophyll indices } \\
\hline Photochemical Reflectance Index (570) & $P R I_{570}=\left(R_{570}-R_{531}\right) /\left(R_{570}+R_{531}\right)$ & [40] \\
\hline \multicolumn{3}{|l|}{ Chlorophyll $\mathrm{a}+\mathrm{b}$ indices } \\
\hline Vogelmann & $V O G 1=R_{740} / R_{720}$ & {$[41]$} \\
\hline Gitelson \&Merzlyak indices & $G M 1=R_{750} / R_{550}$ & {$[42]$} \\
\hline Pigment Specific Simple Ratio Chlorophyll b & $P S S R b=R_{800} / R_{650}$ & {$[43]$} \\
\hline $\begin{array}{l}\text { Transformed Chlorophyll Absorption in } \\
\text { Reflectance Index }\end{array}$ & $T C A R I=3 \cdot\left[\left(R_{700}-R_{670}\right)-0.2 \cdot\left(R_{700}-R_{550}\right) \cdot\left(R_{700} / R_{670}\right)\right.$ & [44] \\
\hline Transformed Chlorophyll Absorption in & TCARI/OSAVI & \\
\hline $\begin{array}{l}\text { Reflectance Index/Optimized Soil-Adjusted } \\
\text { Vegetation Index }\end{array}$ & $=\frac{3 \cdot\left[\left(R_{700}-R_{670}\right)-0.2 \cdot\left(R_{700}-R_{550}\right) \cdot\left(R_{700} / R_{670}\right)\right.}{\left((1+0.16) \cdot\left(R_{800}-R_{670}\right) /\left(R_{800}+R_{670}+0.16\right)\right)}$ & [44] \\
\hline \multicolumn{3}{|l|}{$\mathrm{R} / \mathrm{G} / \mathrm{B}$ indices } \\
\hline Redness index & $R=R_{700} / R_{670}$ & [45] \\
\hline Blue/green indices & $B G I 1=R_{400} / R_{550}$ & [46] \\
\hline Lichtenhaler index & $L I C 3=R_{440} / R_{740}$ & [47] \\
\hline \multicolumn{3}{|l|}{ Carotenoid indices } \\
\hline Pigment Specific Simple Ratio Carotenoids & $P S R R c=R_{800} / R_{500}$ & [43] \\
\hline$R_{515} / R_{570}$ & $R_{515} / R_{570}$ & {$[27]$} \\
\hline$R_{515} / R_{670}$ & $R_{515} / R_{670}$ & [27] \\
\hline \multicolumn{3}{|l|}{ Fluorescence } \\
\hline$F L D$ & FLD3 $(747 ; 762 ; 780)$ & {$[46,48,49]$} \\
\hline \multicolumn{3}{|l|}{ Plant disease index } \\
\hline Healthy-index & $H I=\frac{R_{534}-R_{698}}{R_{534}+R_{698}}-\frac{1}{2} \cdot R_{704}$ & {$[50]$} \\
\hline
\end{tabular}

The Fraunhofer Line Depth (FLD) principle calculated from a total of three bands (FLD3) was applied to the hyperspectral radiance imagery to quantify the fluorescence signal as described by Zarco-Tejada et al. [27]. The bands required for the FLD3 method were the band inside de $\mathrm{O}_{2}-\mathrm{A}$ feature (the "in" wavelength indicates the radiance at L762 nm) and the radiances at two wavelengths outside and on either side of the $\mathrm{O}_{2}$-A feature, referred as the "out" bands (L750 and L780 nm). Previous studies demonstrated successful results in retrieving the chlorophyll fluorescence signal using the micro-hyperspectral imager due to the large spectral oversampling (1.85-nm sampling interval) and $6.4 \mathrm{~nm}$ bandwidths [12,27,51].

The thermal camera (FLIR SC655, FLIR Systems, USA) delivered $640 \times 480$ pixel resolution and was equipped with a $24.5 \mathrm{~mm}$ f1.0 lens, connected to a computer via USB 2.0 protocol. This camera operates with a thermoelectric (TE) cooling stabilization, giving us high sensitivity below $50 \mathrm{mK}$. The spectral response was in the range of 7.5-13 $\mu \mathrm{m}$. Radiometric calibration was conducted in the laboratory using a blackbody (model P80P, Land Instruments, Dronfield, UK) at varying target and ambient temperatures and through vicarious calibrations using surface temperature measurements. Surface temperature was obtained applying atmospheric correction methods to thermal imager data based on MODTRAN radiative transfer code, which models the atmospheric transmissivity and 
longwave upwelling thermal radiation. Downwelling thermal radiation was measured in the field with a thermal sensor (LaserSight, Optris, Germany). Since only vegetation temperature is retrieved, surface emissivity is considered as 0.98 as an accepted value for natural vegetation [31]. Local atmospheric conditions such as air temperature, relative humidity and barometric pressure were measured at the time of the flight with a portable weather station (Model WXT510, Vaisala, Finland) (Table 3) and used as input into MODTRAN model. Atmospheric correction methods conducted with single-band thermal cameras were shown to provide successful estimation of vegetation surface temperature [31]. Canopy temperature (Tc), extracted from thermal imagery, minus air temperature (Ta) was calculated as a water stress indicator of olive trees (Tc-Ta).

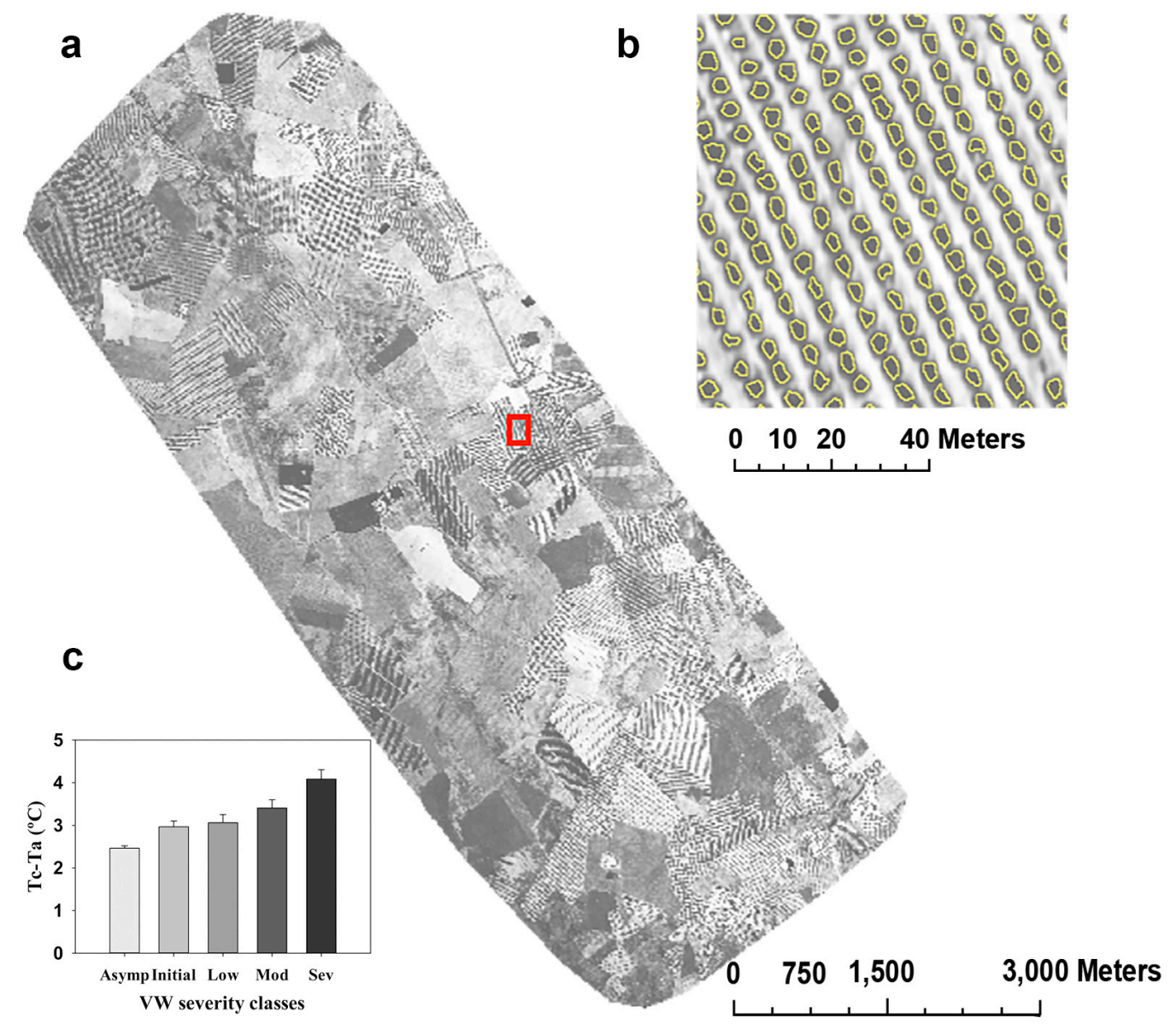

Figure 3. Thermal mosaic (a) obtained with the thermal camera on board the manned platform at $63-\mathrm{cm}$ resolution, enabling pure olive crown identification (b). Pure olive crowns were identified using automatic object-based crown detection. Mean crown normalized temperature (Tc-Ta) calculated from thermal imagery is shown for every Verticillium wilt severity class in (c). Mean values of Tc-Ta were supported by the data of the 9 plots, consisting of 510,98, 64, 46 and 38 olive trees which correspond to asymptomatic, initial, low, moderate and severe severity classes, respectively. Error bars indicate standard errors. Red square (a) is shown in detail in (b).

Single tree crown temperature and reflectance were extracted from high-resolution thermal and hyperspectral imagery (Figures $3 \mathrm{a}$ and $4 \mathrm{a}$ ), respectively, using an automated object-based method. Image segmentation was automatically conducted using Fiji package of ImageJ software [52] to split 
the digital image into multiple regions that made possible to identify single pure tree crowns (Figures $3 \mathrm{~b}$ and $4 \mathrm{~b}$ ). Algorithms developed at the QuantaLab/IAS-CSIC were applied afterwards using GRASS GIS software [53] to extract feature for each object, calculating temperature and reflectance's mean statistics of all the pixels composing each whole crown (Figures $3 \mathrm{c}$ and $4 \mathrm{c}$ ).

Table 3. Local atmospheric conditions measured by a portable weather station during the flight at 30-min interval.

\begin{tabular}{cccccc}
\hline $\begin{array}{c}\text { GMT Time } \\
(\mathbf{h})\end{array}$ & $\begin{array}{c}\text { Air Temperature } \\
\left({ }^{\mathbf{C}} \mathbf{C}\right)\end{array}$ & $\begin{array}{c}\text { Relative Humidity } \\
\mathbf{( \% )}\end{array}$ & $\begin{array}{c}\text { Air VPD } \\
(\mathbf{K P a})\end{array}$ & $\begin{array}{c}\text { Wind Speed } \\
(\mathbf{m} / \mathbf{s})\end{array}$ & $\begin{array}{c}\text { Solar Radiation } \\
\left(\mathbf{W} / \mathbf{m}^{2}\right)\end{array}$ \\
\hline $10: 30$ & 32.4 & 27.3 & 3.5 & 0.7 & 989 \\
$11: 00$ & 33.0 & 26.9 & 3.7 & 0.6 & 984 \\
$11: 30$ & 33.3 & 27.8 & 3.7 & 0.8 & 967 \\
$12: 00$ & 33.8 & 24.9 & 4.0 & 0.9 & 938 \\
\hline
\end{tabular}

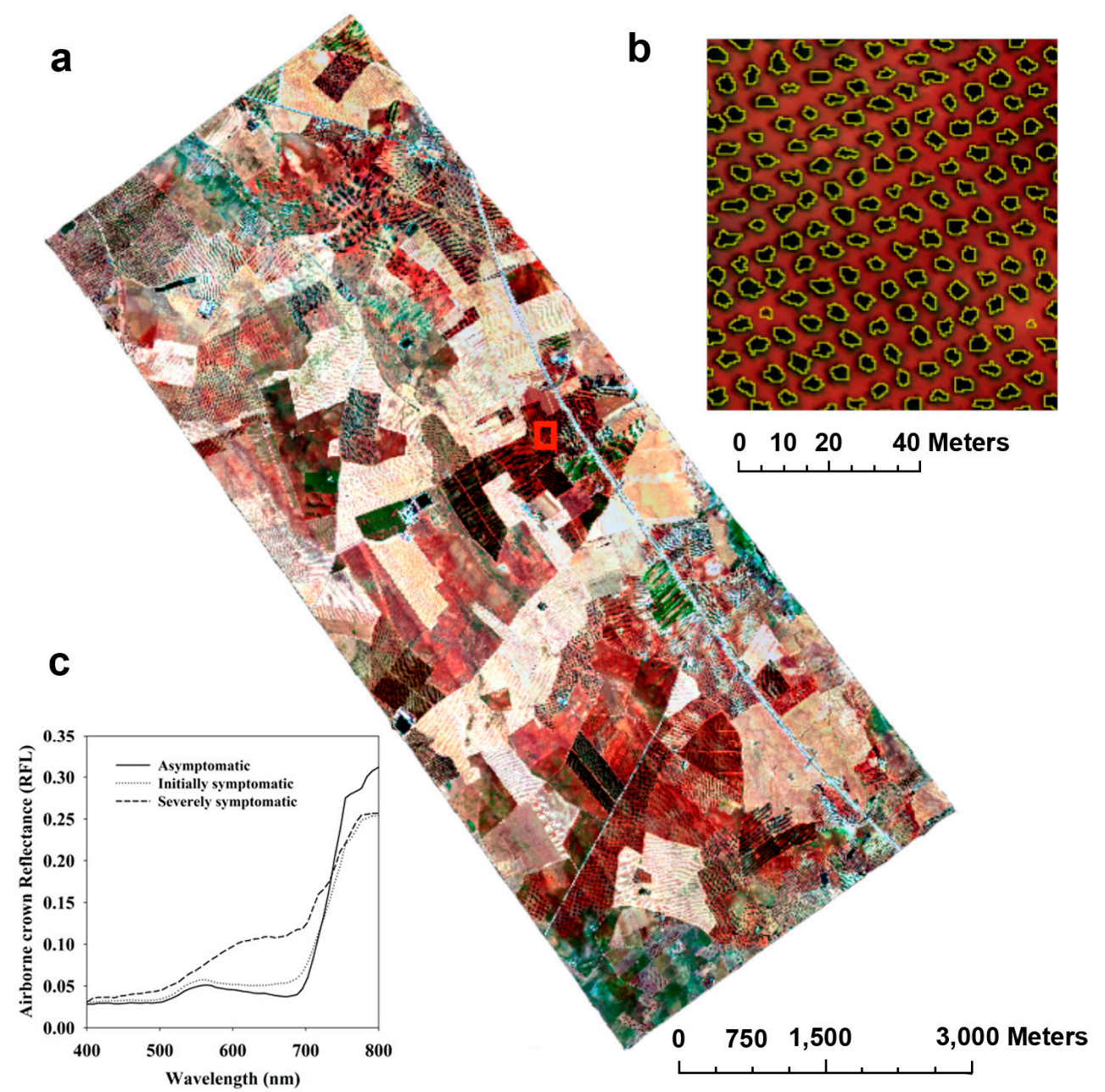

Figure 4. Hyperspectral mosaic (a) obtained with the hyperspectral sensor on board the manned platform at $50-\mathrm{cm}$ resolution. Pure olive crowns were identified using automatic object-based crown detection (b). Sample crown reflectance obtained by the hyperspectral imagery from Verticillium wilt asymptomatic, initially symptomatic and severely symptomatic olive trees is shown in (c). Red square (a) is shown in detail in (b). 


\subsection{Data Analyses}

Multivariate analyses were used to develop models that detected VW infection and severity. The strength of association among normalized canopy temperature (Tc-Ta) and vegetation indices and the VW severity classes was assessed by LDA and SVM methods. Every olive tree assessed was designated with the presence of VW infection and severity of symptoms, as well as Tc-Ta and vegetation indices calculated from the thermal and hyperspectral imagery, respectively.

First, the STEPDISC procedure of SAS software (version 9.4; SAS Institute, Cary, NC, USA) was used to eliminate variables within the model that did not provide additional information or were redundant as determined by the Wilk's lambda method, as well as to add variables outside the model that contribute most to the model [54]. The DISCRIM procedure of SAS was then used to generate a discriminant function capable of determining the classification accuracy of the dataset, based on the pooled covariance matrix and the prior probabilities of the classification groups. Due to the fact that the data were not normally distributed, a non-parametric discriminant analysis was conducted specifying a $\mathrm{k}$-value for the k-nearest-neighbour rule. In this study, we used a k-value of 4, so each observation is classified into a VW severity class focusing on the information from its four nearest neighbours. A dataset of 756 olive trees was created by randomly selecting the $10 \%$ of the asymptomatic trees and including all the trees belonged to the symptomatic VW severity classes. This set was used to run the STEPDISC selected model and then DISCRIM for classifying VW severity groups. Then, the classification accuracy of the selected model was evaluated by calculating the overall accuracy value and the kappa $(\kappa)$ coefficient, which gives an overall accuracy assessment for the classification based on commission and omission error for all classes. The data obtained from the stepwise analysis were further subjected to a canonical discriminant analysis using the CANDISC procedure of SAS to separate classification variables (VW severity classes) based on linear combinations of the quantitative variables (Tc-Ta and vegetation indices). The linear combinations of variables (canonical variates) were then correlated with the original VW severity classes. Canonical variates means (centroid values) were calculated for each classification variable and significance between means was determined using Mahalanobis distance [54]. Individual values for each canonical variate were plotted in a bi-plot for the first and second canonical variables and for the first and third ones.

SVM analysis calculations were conducted using R software [55] with the e1071 [56] package which provides an interface to the open source machine learning library libsvm [57]. For multiclass classification with $\mathrm{k}$ classes, libsvm uses the one-against-one approach, in which $\mathrm{k}(\mathrm{k}-1) / 2$ binary classifiers are trained and the appropriate class is found by a voting scheme. SVM conducted nonlinear classifications using kernel functions and introducing a cost parameter $\mathrm{C}$ to quantify the penalty of misclassification errors. The radial basis function kernel was used in this study because it has fewer parameter values to predefine and yet has been found at least as robust as other kernel types [58,59]. As shown in the Equation (1) of this kernel, the only parameter that needs to be predefined is $\gamma$ :

$$
K\left(x_{i}, x_{j}\right)=e^{-\gamma \cdot\left\|x_{i}-x_{j}\right\|^{2}}
$$

In order to specify the best radial basis function and to find an appropriate factor for penalizing classification errors, the parameter $\mathrm{C}$ and $\gamma$ have to be optimized. In this respect, we applied a grid search method using cross validation approach as recommended by Hsu et al. [60]. The main idea 
behind the grid search method is that different pairs of parameters are tested ( $\mathrm{C}$ and $\gamma$ in this case) and the one with the highest cross validation accuracy is selected.

\section{Results}

In the summer of $2013,4.94 \%$ of the trees assessed at the field level were infected by VW, with a mean DS in symptomatic trees of 1.41 (0-4 rating scale). Taking into account symptomatic trees, $40.08 \%$ showed initial DS symptoms, $25.92 \%$ had low DS symptoms, $18.62 \%$ had moderate DS symptoms and $15.38 \%$ of symptomatic trees had severe DS symptoms.

Table 4. Variables selected from normalized canopy temperature (Tc-Ta) and vegetation indices in the forward stepwise discriminant analysis to determine the severity of Verticillium dahliae infection in olive trees.

\begin{tabular}{cccccc}
\hline Source & Wilks' Lambda & Partial R-Square & $\boldsymbol{F}$ Value & Pr $>\boldsymbol{F}$ & Pr $<$ Lambda \\
\hline OSAVI & 0.833 & 0.1666 & 37.52 & $<0.0001$ & $<0.0001$ \\
LIC3 & 0.718 & 0.1385 & 30.13 & $<0.0001$ & $<0.0001$ \\
Tc-Ta & 0.676 & 0.0585 & 11.63 & $<0.0001$ & $<0.0001$ \\
GM1 & 0.586 & 0.0397 & 7.71 & $<0.0001$ & $<0.0001$ \\
$\mathrm{R}_{515} / \mathrm{R}_{570}$ & 0.610 & 0.0375 & 7.26 & $<0.0001$ & $<0.0001$ \\
PRI $570_{\text {R }}$ & 0.565 & 0.0349 & 6.74 & $<0.0001$ & $<0.0001$ \\
TCARI/OSAVI & 0.654 & 0.0321 & 6.20 & $<0.0001$ & $<0.0001$ \\
EVI & 0.634 & 0.0304 & 5.86 & 0.0001 & $<0.0001$ \\
TCARI & 0.501 & 0.0295 & 5.61 & 0.0002 & $<0.0001$ \\
MTVI1 & 0.549 & 0.0289 & 5.52 & 0.0002 & $<0.0001$ \\
$\mathrm{R}_{515} / \mathrm{R}_{670}$ & 0.464 & 0.0288 & 5.43 & 0.0003 & $<0.0001$ \\
NDVI & 0.455 & 0.0200 & 3.73 & 0.0051 & $<0.0001$ \\
BGI1 & 0.516 & 0.0198 & 3.73 & 0.0052 & $<0.0001$ \\
PSSRc & 0.483 & 0.0191 & 3.58 & 0.0066 & $<0.0001$ \\
TVI & 0.447 & 0.0183 & 3.42 & 0.0088 & $<0.0001$ \\
MSR & 0.492 & 0.0165 & 3.08 & 0.0156 & $<0.0001$ \\
HI & 0.435 & 0.0156 & 2.90 & 0.0213 & $<0.0001$ \\
FLD3 & 0.534 & 0.0148 & 2.77 & 0.0262 & $<0.0001$ \\
VOG & 0.526 & 0.0143 & 2.68 & 0.0310 & $<0.0001$ \\
PSSRb & 0.542 & 0.0132 & 2.49 & 0.0421 & $<0.0001$ \\
RDVI & 0.442 & 0.0103 & 1.91 & 0.1067 & $<0.0001$ \\
\hline
\end{tabular}

In the forward stepwise discriminant analysis, 22 out of 34 indices were selected (Table 4). In this model, Tc-Ta and the indices calculated from the thermal and hyperspectral imagery, respectively, that contributed most (partial $R$-square $>0.05$ ) to discriminate among VW severity classes were OSAVI, LIC3 and normalized canopy temperature $(\mathrm{Tc}-\mathrm{Ta}$ ), followed (partial $R$-square $>0.03<0.05$ ) by GM1, $\mathrm{R}_{515} / \mathrm{R}_{570}$, PRI 570 , red index (R) and TCARI/OSAVI. HI, FLD3, VOG, PSSRb and RDVI showed the lowest contribution (partial $R$-square $<0.015$ ) to the discriminant function (Table 4). Use of LDA allowed classifying the sampled olive trees in a given VW severity class. $71.4 \%, 75.0 \%, 78.3 \%$ and $76.3 \%$ of the initial, low, moderate and severe VW affected trees were correctly classified, respectively 
(Table 5). Interestingly, all symptomatic trees were correctly classified and 55.5\% of the asymptomatic plants that were considered symptomatic in the analysis were classified as plants with initial symptoms, the lowest severity class. Overall, the classification accuracy of the model was 59.0\% (Table 5) and the $\kappa$ value 0.487 (95\% confident interval $0.437-0.536)$. The degree to which the five VW severity categories are separated is measured by the Mahalanobis distance between centroid values for each VW severity category (Table 6). As expected, all pairwise distances between the five VW severity categories were statistically significant $(p<0.005)$.

Table 5. Confusion matrix for Verticillium wilt severity classes using the linear discriminant classification based on the indices selected by the forward stepwise discriminant analysis.

\begin{tabular}{|c|c|c|c|c|c|c|}
\hline \multirow{2}{*}{ Prediction } & \multicolumn{5}{|c|}{ Ground Truth } & \multirow{2}{*}{$\begin{array}{c}\text { Class } \\
\text { Precision }\end{array}$} \\
\hline & Asymptomatic & Initial & Low & Moderate & Severe & \\
\hline Asymptomatic & 263 & 0 & 0 & 0 & 0 & $100 \%$ \\
\hline Initial & 137 & 70 & 5 & 1 & 1 & $32.7 \%$ \\
\hline Low & 48 & 15 & 48 & 2 & 4 & $41.0 \%$ \\
\hline Moderate & 37 & 6 & 6 & 36 & 4 & $40.5 \%$ \\
\hline Severe & 25 & 7 & 5 & 7 & 29 & $76.3 \%$ \\
\hline Class recall & $51.6 \%$ & $71.4 \%$ & $75.0 \%$ & $78.3 \%$ & $76.3 \%$ & $59.0 \%$ \\
\hline
\end{tabular}

Table 6. Squared Mahalanobis distances for Verticillium wilt severity classes obtained in a forward stepwise discriminant analysis.

\begin{tabular}{|c|c|c|c|c|c|}
\hline \multirow[b]{2}{*}{ VW severity class } & \multicolumn{5}{|c|}{ Squared Mahalanobis distance } \\
\hline & Asymptomatic & Initial & Low & Moderate & Severe \\
\hline Asymptomatic & - & 3.102 & 7.032 & 9.704 & 18.410 \\
\hline Initial & 3.102 & - & 2.385 & 5.545 & 11.067 \\
\hline Low & 7.032 & 2.385 & - & 3.614 & 8.761 \\
\hline Moderate & 9.704 & 5.545 & 3.614 & - & 5.569 \\
\hline \multirow[t]{2}{*}{ Severe } & 18.410 & 11.067 & 8.761 & 5.569 & - \\
\hline & \multicolumn{5}{|c|}{$F$ values } \\
\hline VW severity class & Asymptomatic & Initial & Low & Moderate & Severe \\
\hline Asymptomatic & - & $3.102^{* * *}$ & $7.032^{* * *}$ & $9.704^{* * *}$ & $18.410^{* * *}$ \\
\hline Initial & $3.102^{* * *}$ & - & $2.385^{* *}$ & $5.545^{* * *}$ & $11.067^{* * *}$ \\
\hline Low & $7.032^{* * *}$ & $2.385^{* *}$ & - & $3.614^{* * *}$ & $8.761^{* * *}$ \\
\hline Moderate & $9.704^{* * *}$ & $5.545^{* * *}$ & $3.614^{* * *}$ & - & $5.570^{* * *}$ \\
\hline Severe & $18.410^{* * *}$ & $11.067^{* * *}$ & $8.761^{* * *}$ & $5.570^{* * *}$ & - \\
\hline
\end{tabular}

Tc-Ta and vegetation indices, that were part of the discriminant model shown in Table 4, were used in a canonical discriminant analysis. In this analysis, three canonical functions (variates) showing significant differences $(p<0.0001)$ among VW severity classes were created. The first canonical variate significantly accounted for $42.3 \%$ of the variation while the second and the third ones only accounted for 13.8 and $9.5 \%$ of the variation, respectively. The structural indices (i.e., OSAVI, RDVI, MTVI1 and MSR) dominated the three variates. In addition, the first canonical variate was also 
dominated by positive loadings from Tc-Ta, TCARI, GM1, PSSRb, PRI570, R515/R570 and HI and negative loadings from FLD3. In the second canonical variate positive loadings from PSSRb, VOG, TCARI/OSAVI, BGI1, LIC3 and R515/R670 were found. The third canonical variate was dominated by positive loadings from PSSRc and negative loadings from GM1, PSSRb and R (Table 7). According to canonical loadings, the asymptomatic trees were detected mainly at low Tc-Ta, GM1, PSSRb, PRI570, $\mathrm{R}_{515} / \mathrm{R}_{570}$ and HI, and high structural indices and FLD3 values. As the VW severity increased, the values of Tc-Ta, TCARI, GM1, PSSRb, PRI $570, \mathrm{R}_{515} / \mathrm{R}_{570}$ and HI were higher, and structural indices and FLD3 were lower. Furthermore, the ranges of the indices values became higher as the VW severity level increased. In contrast, blue/green/red indices (BGI1, R and LIC3), chlorophyll (TCARI/OSAVI and VOG) and carotenoid indices ( $\mathrm{R}_{515} / \mathrm{R}_{670}$ and PSSRc) were not able to detect differences among asymptomatic, initial and low severity levels but could discriminate among asymptomatic, moderate and severe levels (Figure 5).

Table 7. Standardized canonical coefficients (SCCs) and correlation coefficients (CCCs) of discriminant canonical functions of canopy normalized canopy temperature (Tc-Ta) and vegetation indices selected by the forward stepwise discriminant analysis that determine Verticillium wilt severity levels.

\begin{tabular}{ccccccc}
\hline \multirow{2}{*}{ Source } & \multicolumn{3}{c}{ SCCs } & \multicolumn{3}{c}{ CCCs } \\
\cline { 2 - 7 } & Variate 1 & Variate 2 & Variate 3 & Variate 1 & Variate 2 & Variate 3 \\
\hline OSAVI & -5.773 & 23.593 & -14.241 & -0.614 & -0.050 & 0.270 \\
LIC3 & -0.262 & 0.775 & 0.206 & -0.585 & -0.090 & -0.297 \\
Tc-Ta & 0.384 & 0.214 & 0.118 & 0.471 & 0.032 & 0.089 \\
GM1 & 3.326 & -0.100 & -6.922 & -0.565 & -0.143 & 0.164 \\
R $_{515} / \mathrm{R}_{570}$ & 1.282 & -0.022 & 0.009 & 0.339 & -0.059 & -0.001 \\
PRI $_{570}$ & 1.149 & 1.137 & 0.035 & 0.342 & 0.080 & 0.142 \\
R & 1.083 & 0.760 & -2.353 & 0.324 & 0.187 & 0.166 \\
TCARI/OSAVI & -0.736 & 1.567 & -0.348 & -0.274 & 0.360 & 0.119 \\
EVI & -3.119 & -9.210 & -2.857 & -0.584 & -0.072 & 0.256 \\
TCARI & 2.036 & -1.356 & 1.153 & -0.459 & 0.163 & 0.142 \\
MTVI1 & -6.244 & 9.113 & -14.574 & -0.559 & -0.016 & 0.285 \\
R $_{515} / R_{670}$ & -0.961 & 2.189 & 1.139 & -0.327 & -0.009 & -0.100 \\
NDVI & -1.867 & -3.687 & 1.187 & -0.618 & -0.054 & 0.196 \\
BGI1 & 0.230 & 0.824 & 0.470 & -0.054 & -0.010 & -0.150 \\
PSSRc & -1.626 & 0.499 & 7.490 & -0.396 & -0.126 & 0.260 \\
TVI & -1.418 & 1.260 & 5.868 & -0.527 & 0.044 & 0.319 \\
MSR & -6.167 & -9.539 & 0.776 & -0.530 & -0.111 & 0.130 \\
HI & 3.354 & -1.410 & 1.030 & -0.471 & -0.024 & -0.146 \\
FLD3 & -0.340 & -0.271 & 0.262 & -0.379 & -0.156 & 0.137 \\
VOG & -1.017 & 1.486 & -0.067 & -0.598 & -0.084 & 0.143 \\
PSSRb & 4.601 & 6.268 & -2.450 & -0.496 & -0.145 & 0.116 \\
RDVI & 15.945 & -18.906 & 24.147 & -0.592 & -0.049 & 0.317 \\
\hline & & & & & &
\end{tabular}


a

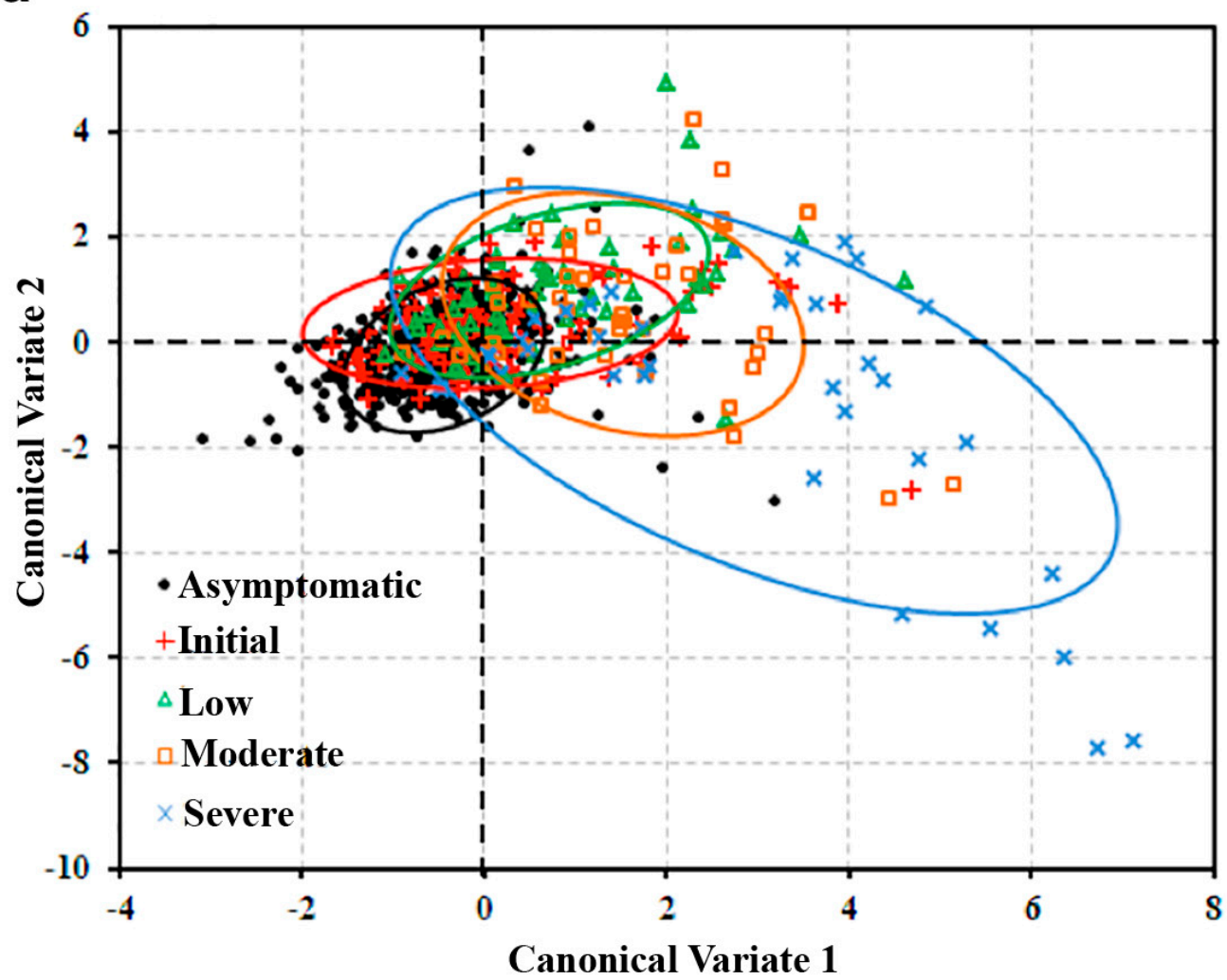

b

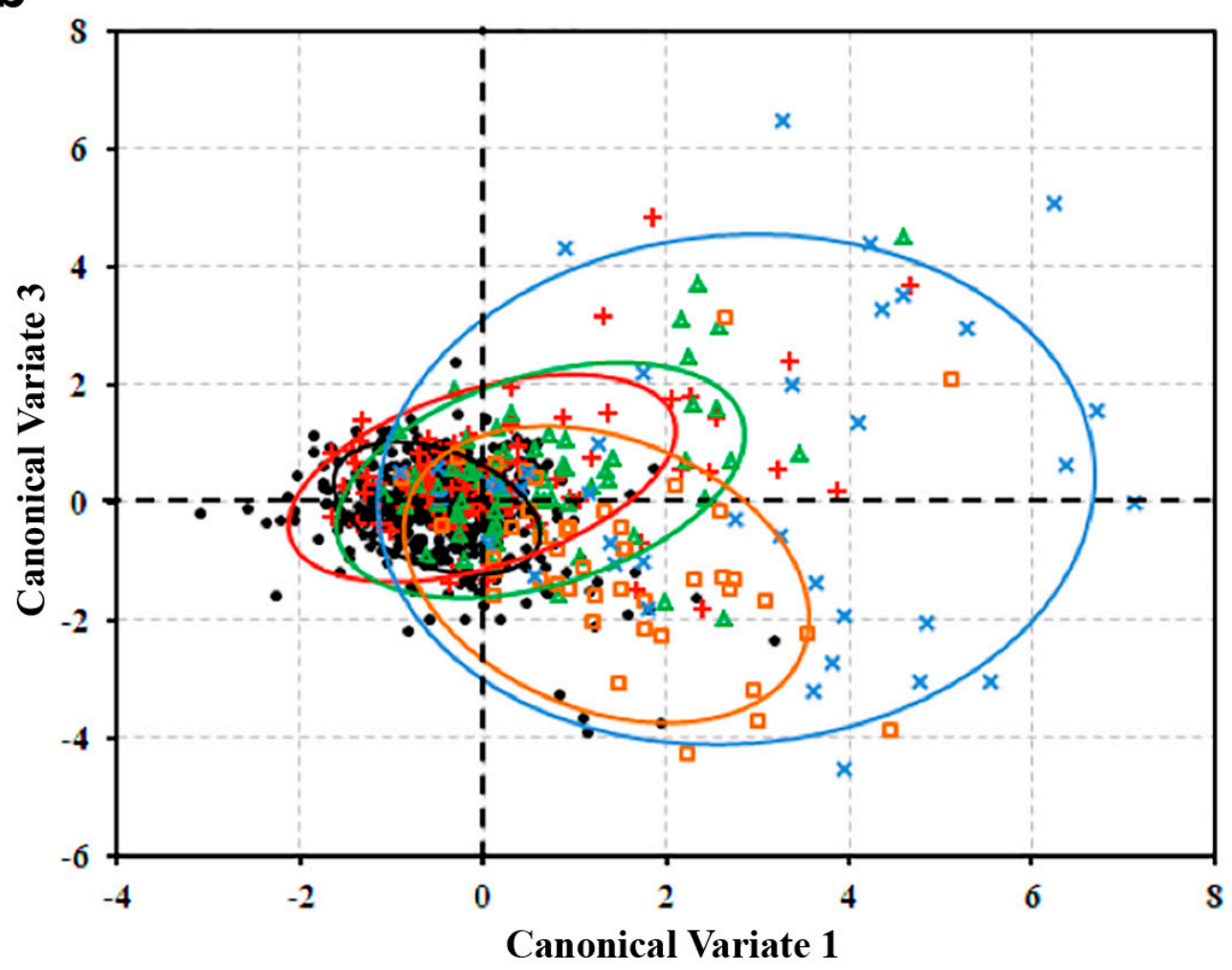

Figure 5. Classification of 756 olive trees assessed in Ecija into five Verticillium wilt severity classes based on (a) the first and second canonical variates and (b) the first and third canonical variates, from the canonical discriminant analysis. 
SVM classification was also conducted for the differentiation among VW severity classes using the vegetation indices selected in the forward stepwise discriminant analysis showed in Table 4 . Table 8 summarizes the results of the SVM model, which classified every olive tree assessed at field level in a given VW severity class. The overall classification accuracy was $79.2 \%$ and the $\kappa$ value $0.495(95 \%$ confident interval 0.433-0.557), that was slightly higher than that obtained by LDA. 99.4\% of asymptomatic trees were correctly classified in the asymptomatic class and the $14.3 \%, 40.6 \%, 67.4 \%$ and $55.3 \%$ of the initial, low, moderate and high severity infected VW trees were correctly classified, respectively. In contrast to LDA results, SVM was very effective in correctly identifying asymptomatic trees but showed lower power to identify symptomatic trees. Mostly, this classification method failed in separating between plants infected at early stages of VW development. Thus, $63.2 \%$ and $56.3 \%$ of trees showing initial or low VW severity were considered as asymptomatic (Table 8). The maps generated in Figure 6 represent the spatial pattern of VW severity classes assessed at field level and the severity classes predicted by LDA and SVM. Such maps showed an overestimation of VW symptomatic classes by LDA while SVM revealed an underestimation of these classes.

Table 8. Confusion matrix for Verticillium wilt severity classes using the support vector machine classification based on the indices selected by the forward stepwise discriminant analysis.

\begin{tabular}{ccccccc}
\hline \multirow{2}{*}{ Prediction } & \multicolumn{5}{c}{ Ground Truth } & $\begin{array}{c}\text { Class } \\
\text { Precision }\end{array}$ \\
\cline { 2 - 6 } Asymptomatic & Initial & Low & Moderate & Severe & Precis \\
\hline Asymptomatic & 507 & 79 & 36 & 15 & 11 & $78.2 \%$ \\
Initial & 0 & 14 & 1 & 0 & 0 & $93.3 \%$ \\
Low & 3 & 3 & 26 & 0 & 3 & $74.3 \%$ \\
Moderate & 0 & 2 & 1 & 31 & 3 & $83.8 \%$ \\
Severe & 0 & 0 & 0 & 0 & 21 & $100 \%$ \\
Class recall & $99.4 \%$ & $14.3 \%$ & $40.6 \%$ & $67.4 \%$ & $55.3 \%$ & $79.2 \%$ \\
\hline
\end{tabular}

When analysing the different plots separately, the LDA model reached classification accuracies between $60.0 \%$ and $82.9 \%$ and $\kappa$ ranged from 0.382 to 0.808 (Table 9). On the other hand, SVM model showed better classification accuracies between $68.5 \%$ and $92.7 \%$ and slightly lower $\kappa$ ranging from 0.230 to 0.798 . Applying the forward stepwise discriminant analysis to each plot separately, the indices which contributed most to discriminate among VW severity classes for the global model were selected in the majority of plots. Interestingly, Tc-Ta was selected in all plots, $\mathrm{R}$ in seven plots and TCARI/OSAVI in six plots. In addition, structural indices were selected in no more than three plots in contrast to the high discrimination power showed in the global model (Table 10). 
VW severity classes

LDA

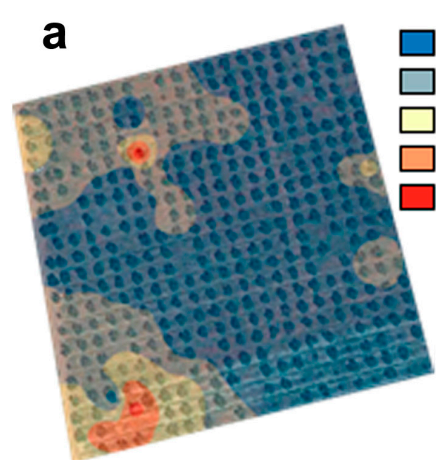

SVM

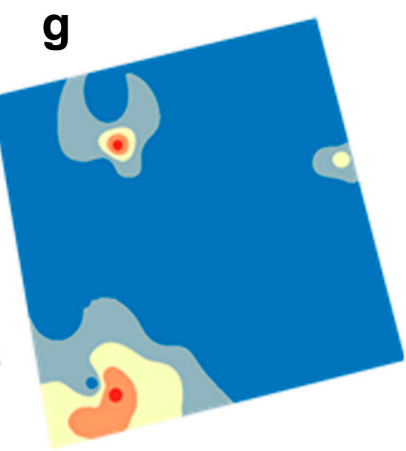

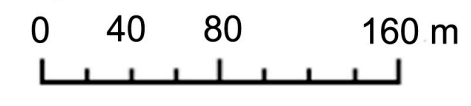
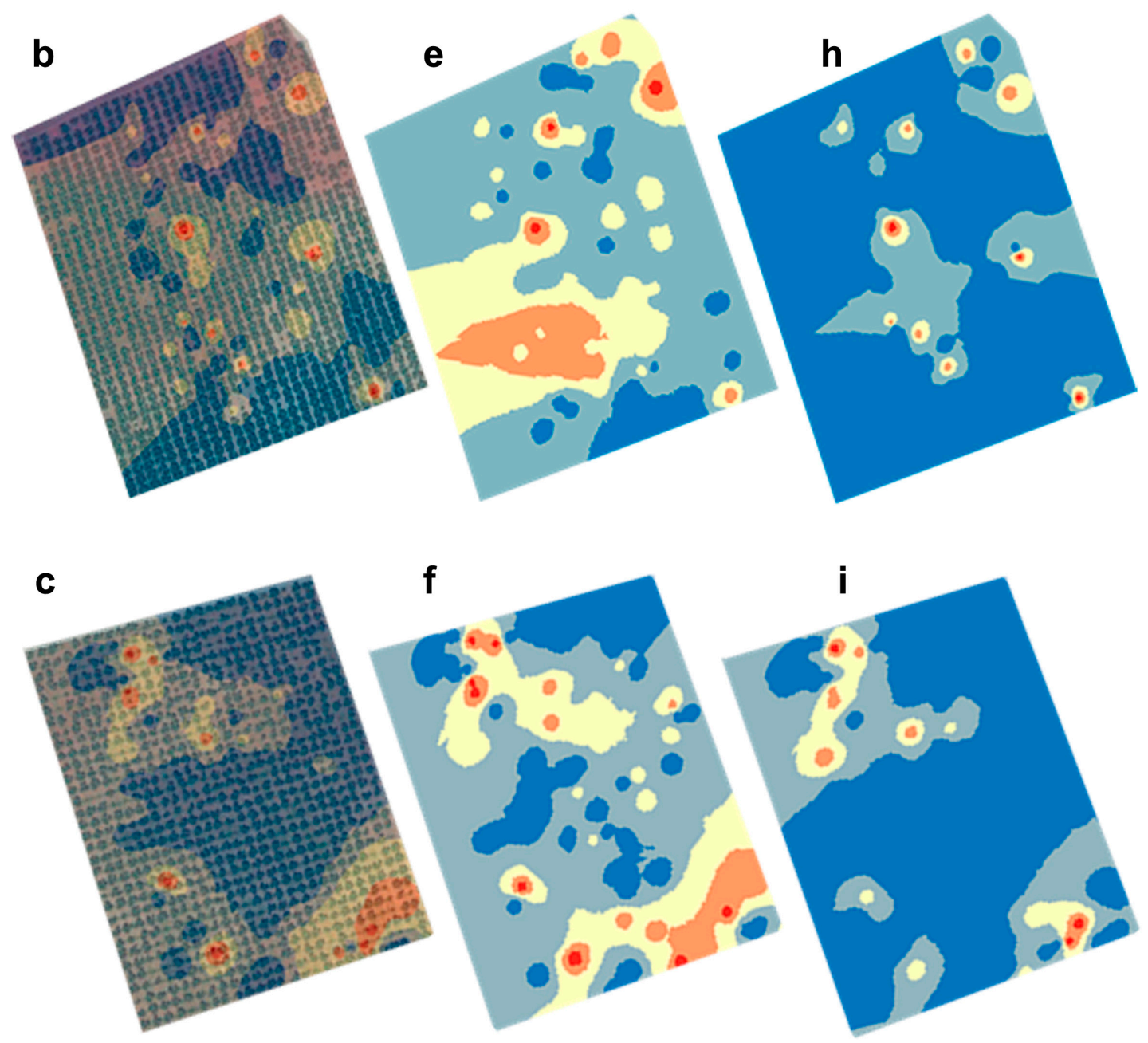

Figure 6. Spatial distribution of Verticillium wilt severity classes assessed at field level $(\mathbf{a}, \mathbf{b}, \mathbf{c})$ and the severity classes predicted by the linear discriminant analysis (LDA) $(\mathbf{d}, \mathbf{e}, \mathbf{f})$ and support vector machine $(\mathrm{SVM})$ methods $(\mathbf{g}, \mathbf{h}, \mathbf{i})$ in three different plots. 
Table 9. Overall accuracy and kappa obtained from the linear discriminant analysis (LDA) and the support vector machine (SVM) classification methods to detect Verticillium wilt severity levels for the individual olive plots assessed and for the all the plots together.

\begin{tabular}{ccccc}
\hline \multirow{2}{*}{ Plot } & \multicolumn{2}{c}{ LDA } & \multicolumn{2}{c}{ SVM } \\
\cline { 2 - 5 } & Overall accuracy & Kappa & Overall accuracy & Kappa \\
\hline 1 & 0.600 & 0.486 & 0.862 & 0.712 \\
2 & 0.796 & 0.761 & 0.880 & 0.788 \\
3 & 0.684 & 0.543 & 0.785 & 0.230 \\
4 & 0.753 & 0.766 & 0.685 & 0.538 \\
5 & 0.600 & 0.382 & 0.825 & 0.250 \\
6 & 0.732 & 0.593 & 0.902 & 0.787 \\
7 & 0.600 & 0.523 & 0.911 & 0.785 \\
8 & 0.829 & 0.808 & 0.927 & 0.798 \\
9 & 0.613 & 0.415 & 0.793 & 0.555 \\
All plots & 0.590 & 0.487 & 0.792 & 0.495 \\
\hline
\end{tabular}

Table 10. Variables selected in the forward stepwise discriminant analysis to distinguish among Verticillium wilt severity levels for each individual plot assessed.

\begin{tabular}{|c|c|c|c|c|c|c|c|c|c|}
\hline \multirow{2}{*}{ Source } & \multicolumn{9}{|c|}{ Plot } \\
\hline & 1 & 2 & 3 & 4 & 5 & 6 & 7 & 8 & 9 \\
\hline OSAVI & & $X$ & & $\mathrm{X}$ & & & & & \\
\hline LIC3 & $\mathrm{X}$ & $\mathrm{X}$ & & & & $\mathrm{X}$ & & $\mathrm{X}$ & $\mathrm{X}$ \\
\hline Tc-Ta & $\mathrm{X}$ & $X$ & $\mathrm{X}$ & $\mathrm{X}$ & $X$ & $\mathrm{X}$ & $X$ & $X$ & $\mathrm{X}$ \\
\hline GM1 & & $X$ & $\mathrm{X}$ & & & $X$ & & & $\mathrm{X}$ \\
\hline $\mathrm{R}_{515} / \mathrm{R}_{570}$ & & $\mathrm{X}$ & & $\mathrm{X}$ & & $\mathrm{X}$ & $\mathrm{X}$ & $\mathrm{X}$ & \\
\hline $\mathrm{PRI}_{570}$ & & & & $\mathrm{X}$ & & & & & \\
\hline $\mathrm{R}$ & & $X$ & & $\mathrm{X}$ & $\mathrm{X}$ & $\mathrm{X}$ & $\mathrm{X}$ & $X$ & $\mathrm{X}$ \\
\hline TCARI/OSAVI & $\mathrm{X}$ & $X$ & $X$ & $\mathrm{X}$ & & $\mathrm{X}$ & & $X$ & \\
\hline EVI & $\mathrm{X}$ & $\mathrm{X}$ & & & $\mathrm{X}$ & & & & \\
\hline TCARI & & & & $\mathrm{X}$ & & & & $\mathrm{X}$ & $\mathrm{X}$ \\
\hline MTVI1 & & & & & & & & & \\
\hline $\mathrm{R}_{515} / \mathrm{R}_{670}$ & & & & $\mathrm{X}$ & & & & & \\
\hline NDVI & & $\mathrm{X}$ & $\mathrm{X}$ & & & & & $\mathrm{X}$ & \\
\hline BGI1 & & $\mathrm{X}$ & $\mathrm{X}$ & & & & & & \\
\hline PSSRc & & & $\mathrm{X}$ & $\mathrm{X}$ & & & & & \\
\hline TVI & & $X$ & & $\mathrm{X}$ & & & & & \\
\hline MSR & & & & & & & & & \\
\hline HI & & & $\mathrm{X}$ & $\mathrm{X}$ & & & & $\mathrm{X}$ & \\
\hline FLD3 & & $\mathrm{X}$ & & $\mathrm{X}$ & & & $\mathrm{X}$ & $\mathrm{X}$ & $\mathrm{X}$ \\
\hline VOG & & $\mathrm{X}$ & & & & $X$ & & & \\
\hline PSSRb & & $X$ & & $\mathrm{X}$ & & & & & \\
\hline RDVI & & $X$ & & & & & & & \\
\hline
\end{tabular}




\section{Discussion}

Remote sensing has been demonstrated to be a useful decision support system for crop management $[9,10]$. In combination with powerful data analysis methods, remote sensing becomes an essential tool for integrated disease management. In particular, the detection of olive trees infected by $V$. dahliae would be of importance for the management of VW, particularly at early stages of $V$. dahliae infection. The early detection of $V$. dahliae infection would help to avoid the spread of the pathogen to new areas, especially if they are free of $V$. dahliae, and to improve the use of available control measures $[2,6,61]$. A recent study has demonstrated early detection of VW using high-resolution thermal and hyperspectral imagery in two commercial olive orchards [12]. V. dahliae penetrates into the plant roots, blocking water flow and reducing the transpiration rate which induced the stomata closure. Consequently, evaporative cooling is reduced and canopy temperature increases. Moreover, the reduction in photosynthesis caused by $V$. dahliae infection leads to an increase of the dissipation of energy by fluorescence. Considering these changes, several studies showed the feasibility of VW detection of olive trees at leaf and local scale even before characteristic disease symptoms were visible using normalized temperature, chlorophyll content, chlorophyll fluorescence and blue $\mathrm{B} / \mathrm{BG} / \mathrm{BR}$ indices [12,13]. However, to our knowledge no studies have explored the robustness of these methods using narrow-band indices and thermal imagery for the early detection of VW in larger olive growing areas (i.e., thousands of hectares) characterized by large differences in crop age, tree-crown size, olive cultivars, crop managements and classes of disease severity. Therefore, the main objective of this study was to develop a robust and accurate method to detect the stress caused by $V$. dahliae infection and severity in olive growing areas to design localized VW control strategies at large scale.

In our study, thermal and hyperspectral imagery were obtained from the study area, obtaining the data for each individual tree of normalized canopy temperature (Tc-Ta) and 260 spectral bands. As the number of spectral bands increases, the analysis of the data becomes more limited and complex so a dimensional reduction is required without losing important information [62]. Thus, the calculation of vegetation indices results in a reduction of the data dimension, which may be also useful in effective data analysis for disease discrimination [9]. Since vegetation indices commonly used in remote sensing of vegetation are disease-specific indices, in this study we used the indices that Calderón et al. [12] proved to be good indicators of VW at early and advanced stages of disease development. Then, these indices were introduced in a forward stepwise discriminant analysis to select the ones contributing the most to the discriminatory power among VW severity classes, so that the spectral dimensionality was further reduced. Results of this work demonstrates that Tc-Ta, structural (OSAVI, MTVI1, NDVI, TVI, MSR and RDVI), chlorophyll (GM1, TCARI/OSAVI, TCARI, VOG and PSSRb), carotenoid (PSSRc), blue/green BGI1, blue/red LIC3, FLD3 and HI indices were robust VW indicators in agreement with Calderón et al. [12]. However, chlorophyll indices (ZM [63], GM2 [42], PSSRa [43], mCAI [64]), SIPI [65], PRI515 [66], blue (B) [12] and the blue/red ratios BR1 and BR2 [27] were not good indicators in the present study, demonstrating to be influenced by the variation of agronomic characteristics within large olive areas. By contrast, indices that were not robust in Calderon et al. [12], such as $\mathrm{PRI}_{570}$, red (R), $\mathrm{R}_{515} / \mathrm{R}_{570}, \mathrm{R}_{515} / \mathrm{R}_{670}$, were demonstrated to be useful for VW detection in this study. At large scale, these indices may work better detecting VW at advanced stages where crown 
structural and density changes due to disease stress are more differentiated as the variation in agronomic characteristics within the study area is bigger. When applying the forward stepwise discriminant analysis to individual plots, the indices selected in the analysis including all plots demonstrated their robustness for each plot analyzed separately, with the exception of structural indices. The non-inclusion of structural indices by the stepwise discriminant analysis may be due to the lower within plot variability on crown structure and density according to the presence of fewer differences in agronomic characteristics.

In remote sensing for plant disease detection, different classification methods have been used in order to maximize information obtained from imagery. In this study, two different supervised classification methods were used for data analysis, the LDA and the non-linear SVM methods. Both classification methods have shown good results for detecting plant diseases at small scale $[14,21,67,68]$ but to our knowledge have not been used previously for the detection of plant diseases at large scale, such as the one of this study. For the whole dataset, LDA reached an overall accuracy of $59.0 \%$ and a $\kappa$ of 0.487 while SVM showed a higher overall accuracy, $79.2 \%$, and a slightly higher $\kappa, 0.495$. LDA correctly classified the $51.6 \%$ of the asymptomatic trees while SVM classified 99.4\%. However, LDA was more efficient in classifying the trees at initial and low VW severity levels, reaching accuracies of $71.4 \%$ and $75.0 \%$, respectively, in comparison with the $14.3 \%$ and $40.6 \%$ obtained by SVM. Both classification methods showed an increase of the class accuracy (class recall) as the VW severity level increased. It is due to the higher differences found in Tc-Ta and vegetation indices values with the increase in VW severity level when is compared to the asymptomatic class [12]. When considering individual olive orchards, the overall classification accuracy reached by both classification methods were generally higher than that attained with the whole dataset. The lower within plot variability on agronomic characteristics could be responsible for this effect. In addition, SVM obtained higher overall accuracies and $\kappa$ than LDA.

Recently, there has been growing interest in exploring the potential of SVM for early detection of plant diseases. Thus, Rumpf et al. [21] used this approach to discriminate between healthy sugar beet leaves from that infected with various foliar pathogens that included Cercospora beticola, Uromyces beate and Erysiphe betae at early stages of pathogenesis based on hyperspectral data. Similarly, Römer et al. [68] detected wheat leaf rust at a pre-symptomatic stage using UV-light induced fluorescence data analysed by SVM classification methods. Nevertheless, in our study, although SVM reached the highest overall accuracy, LDA classified olive trees better at the initial and low VW severity levels with accuracies of $71.4 \%$ and $75.0 \%$, respectively, in comparison with the $14.3 \%$ and $40.6 \%$ obtained by SVM. After LDA, a canonical discriminant analysis was conducted to reduce the dimensionality of the variables included in the model. Thus, three canonical variates were derived accounting for $42.3 \%, 13.8 \%$ and $9.5 \%$ of the variation, respectively. The first canonical variate allowed the discrimination between the asymptomatic and symptomatic VW severity classes, particularly at the initial and low levels. This variate was dominated by Tc-Ta, structural indices (RDVI, MTVI1, MSR, OSAVI and EVI), PRI570, FLD3, HI, chlorophyll (TCARI, GM1, PSSRb) and carotenoid ( $\left.\mathrm{R}_{515} / \mathrm{R}_{570}\right)$ indices, whose value ranges increased as the severity level increased. The second and third canonical variates were able to distinguish between asymptomatic and VW severity levels at advanced stages of disease development. These variates were dominated by the blue/green/red 
(BGI1, R and LIC3), structural (OSAVI, RDVI, NDVI, EVI, TVI, RDVI, MTVI1 and MSR), chlorophyll (TCARI/OSAVI, PSSRb, GM1 and VOG) and carotenoid indices (R515/R670 and PSSRc).

Canopy temperature has proven to be useful to detect root impairment caused by $V$. dahliae in several studies. Nilsson [69] reported that oilseed rape plants infected with $V$. dahliae showed leaf temperatures 5-8 ${ }^{\circ} \mathrm{C}$ higher than non-infected plants. In addition, normalized leaf and canopy temperature were identified as early indicators of $V$. dahliae infection in olive trees [12,13], showing up to $2{ }^{\circ} \mathrm{C}$ higher in VW infected trees. Hyperspectral reflectance differences were also demonstrated to identify VW in cotton and olive crops. Chen et al. [70,71] confirmed that the spectral characteristics of cotton infected plants changed gradually with the increase in the visible region with disease severity, while a reduction occurred in the near-infrared region. Moreover, results obtained in this study at canopy level confirmed those obtained at leaf level under controlled conditions by Calderón et al. [13], who identified SPAD readings (chlorophyll content) and chlorophyll fluorescence as early VW indicators. In addition, these results were also in agreement with the study carried out by Calderón et al. [12] at canopy level in two olive commercial orchards, proving the potential for early detection of $V$. dahliae infection in olive crops using hyperspectral imagery acquired with an unmanned aerial vehicle. In that study, FLD3, B, BGI1 and BRI1 were determined as VW indicators at initial stages of disease development. Moreover, Calderón et al. [12] proved structural, chlorophyll, carotenoid and HI indices to be good VW indicators at advanced stages of disease development. In conclusion, Tc-Ta calculated from thermal imagery and chlorophyll fluorescence estimated with the FLD3 in-filling retrieval method from the hyperspectral imagery allowed identifying olive trees at the early stages of disease development as much at orchard scale as at larger scale. Thus, the use of Tc-Ta and FLD3 as early indicators of Verticillium wilt is not influenced by the variation of agronomic characteristics within the study area. However, it is not the case for blue/blue-green/blue-red (B, BG1 and BR1) ratios which were found good indicators of Verticillium wilt at initial and low severity levels at orchard scale but only detected moderate and advanced severity levels at larger scale. Structural, xanthophyll, chlorophyll, carotenoid and disease indices and green/red ratios calculated from hyperspectral imagery proved to be good indicators to detect the presence of moderate to severe damage caused by Verticillium wilt as much at orchard scale as at larger scale.

\section{Conclusions}

In the present study, a procedure to develop a robust and accurate method for the automatic classification of $V$. dahliae infection and severity using remote sensing was assessed at large scale. This study completed the one conducted by Calderón et al. [12] at orchard scale, extrapolating the methods to larger areas comprising several olive orchards differing in soil and crop management characteristics. High-resolution imagery was acquired with a thermal and a hyperspectral camera installed on board a manned platform which flew a 3000-ha commercial olive area. We calculated narrowband hyperspectral indices and normalized canopy temperature (Tc-Ta) from the hyperspectral and thermal imagery and used linear discriminant analysis (LDA) and support vector machine (SVM) methods to discriminate among VW severity classes exploiting the combined information of these indices and Tc-Ta. For the whole dataset, LDA reached an overall accuracy of $59.0 \%$ and a $\kappa$ of 0.487 while SVM obtained a higher overall accuracy, 79.2\%, and a similar $\kappa, 0.495$. However, LDA 
classified better the trees at initial and low severity levels, reaching accuracies of $71.4 \%$ and $75.0 \%$, respectively, in comparison with the $14.3 \%$ and $40.6 \%$ obtained by SVM. Tc-Ta, structural indices (RDVI, MTVI1, MSR, OSAVI and EVI), PRI570, FLD3, HI, chlorophyll (TCARI, GM1, PSSRb) and carotenoid (R515/R570) indices detected VW at early and advanced stages of disease development, while the structural (NDVI and TVI), blue/green/red (BGI1, R and LIC3), chlorophyll (TCARI/OSAVI and VOG) and carotenoid indices ( $\mathrm{R}_{515} / \mathrm{R}_{670}$ and PSSRc) were good indicators of VW at advanced stages. Comparing with the results obtained by Calderón et al. [12], Tc-Ta and FLD3 allowed identifying olive trees at the early stages of disease development as much at orchard scale as at larger scale, being not influenced by the variation of agronomic characteristics within the study area. Structural, xanthophyll, chlorophyll, carotenoid and disease indices and blue/green/red ratios proved to be good indicators to detect the presence of moderate to severe damage caused by VW. These results demonstrate that the methods developed at orchard scale are validated for flights in large areas consisting of olive orchards with different characteristics.

\section{Acknowledgments}

Financial support for this research was provided by Project P08-AGR-03528 from "Consejería de Economía, Innovación y Ciencia" of Junta de Andalucía and the European Social Fund, and projects AGL-2012-37521 and AGL2012-40053-C03-01 from the Spanish "Ministerio de Economía y Competitividad" and the European Social Fund. Rocio Calderón is a recipient of research fellowship BES-2010-035511 from the Spanish "Ministerio de Ciencia e Innovación". David Notario, Alberto Vera, Alberto Hornero, Alfredo Gómez and Rafael Romero are acknowledged for their support during the airborne campaign and the image processing. Guillermo León-Ropero is acknowledged for his technical support in Verticillium wilt assessments.

\section{Author Contributions}

Rocio Calderon, Juan A. Navas-Cortes and Pablo J. Zarco-Tejada conceived and designed the experiments. Rocio Calderón, Juan A. Navas-Cortes and Pablo J. Zarco-Tejada performed the experiments. Rocio Calderón, Juan A. Navas-Cortes and Pablo J. Zarco-Tejada analyzed the data. Juan A. Navas-Cortes and Pablo J. Zarco-Tejada Contributed reagents/materials/analysis tools. Rocio Calderon, Juan A. Navas-Cortes and Pablo J. Zarco-Tejada wrote the paper.

\section{Conflicts of Interest}

The authors declare no conflict of interest.

\section{References}

1. FAOSTAT. Available online: http://faostat.fao.org/ (accessed on 12 December 2014).

2. Jiménez-Díaz, R.M.; Cirulli, M.; Bubici, G.; Jiménez-Gasco, L.M.; Antoniou, P.P.; Tjamos, E.C. Verticillium wilt, a major threat to olive production: Current status and future prospects for its management. Plant Dis. 2012, 96, 304-329. 
3. Jiménez-Díaz, R.M.; Olivares-García, C.; Landa, B.B.; Jiménez-Gasco, M.M.; Navas-Cortés, J.A. A region-wide analysis of genetic diversity in Verticillium dahliae infecting olive in southern Spain and agricultural factors influencing the distribution and prevalence of vegetative compatibility groups and pathotypes. Phytopathology 2011, 101, 304-315.

4. Villalobos, F.J.; Testi, L.; Hidalgo, J.; Pastor, M.; Orgaz, F. Modelling potential growth and yield of olive (Olea europaea L.) canopies. Eur. J. Agron. 2006, 24, 296-303.

5. Tjamos, E.C.; Jiménez Díaz, R.M. Management of disease. In A Compendium of Verticillium Wilt in Tree Species; Hiemstra, J.A., Harris, D.C., Eds.; Posen and Looijen: Wageningen, The Netherlands, 1998; pp. 55-57.

6. Navas-Cortés, J.A.; Landa, B.B.; Mercado-Blanco, J.; Trapero-Casas, J.L.; Rodríguez-Jurado, D.; Jiménez-Díaz, R.M. Spatiotemporal analysis of spread of infections by Verticillium dahliae pathotypes within a high tree density olive orchard in southern Spain. Phytopathology 2008, 98, 167-180.

7. Steiner, U.; Buerling, K.; Oerke, E.-C. Sensor use in plant protection. Gesunde Pflanz. 2008, 60, 131-141.

8. Mahlein, A.-K.; Oerke, E.-C.; Steiner, U.; Dehne, H.-W. Recent advances in sensing plant diseases for precision crop protection. Eur. J. Plant Pathol. 2012, 133, 197-209.

9. Sankaran, S.; Mishra, A.; Ehsani, R.; Davis, C. A review of advanced techniques for detecting plant diseases. Comput. Electron. Agric. 2010, 72, 1-13.

10. Van Alfen, N.K. Reassessment of plant wilt toxins. Ann. Rev. Phytopathol. 1989, 27, 533-550.

11. Hillnhütter, C.; Schweizer, A.; Kühnhold, V.; Sikora, R.A. Remote sensing for the detection of soil-borne plant parasitic nematodes and fungal pathogens. In Precision Crop Protection-The Challenge and Use of Heterogeneity; Oerke, E.-C., Gerhards, R., Menz, G., Sikora, R.A., Eds.; Springer: New York, NY, USA, 2010; pp. 151-165.

12. Calderón, R.; Navas-Cortés, J.A.; Lucena, C.; Zarco-Tejada, P.J. High-resolution airborne hyperspectral and thermal imagery for early detection of Verticillium wilt of olive using fluorescence, temperature and narrow-band spectral indices. Remote Sens. Environ. 2013, 139, 231-245.

13. Calderón, R.; Lucena, C.; Trapero-Casas, J.L.; Zarco-Tejada, P.J.; Navas-Cortés, J.A. Soil temperature determines the reaction of olive cultivars to Verticillium dahliae pathotypes. Plos One 2014, 9, doi:10.1371/journal.pone.0110664.

14. Delwiche, S.R.; Kim, M.S. Hyperspectral imaging for detection of scab in wheat. Proc. SPIE 2000, 4203, doi:10.1117/12.411752.

15. Qin, J.; Burks, T.F.; Kim, M.S.; Chao, K.; Ritenour, M.A. Citrus canker detection using hyperspectral reflectance imaging and PCA-based image classification method. Sens. Instrum. Food Qual. Saf. 2008, 2, 168-177.

16. Delalieux, S.; van Aardt, J.; Keulemans, W.; Schrevens, E.; Coppin, P. Detection of biotic stress (Venturia inaequalis) in apple trees using hyperspectral data: Non-parametric statistical approaches and physiological implications. Eur. J. Agron. 2007, 27, 130-143.

17. Grimm, L.G.; Yarnold, P.R. Reading and Understanding Multivariate Statistics; American Psychological Association: Washington, DC, USA, 1995. 
18. Balakrishnama, S.; Ganapathiraju, A. Linear Discriminant Analysis-A Brief Tutorial; Institute for Signal and Information Processing, Department of Electrical and Computer Engineering, Mississippi State University: Mississippi, MS, USA, 1998.

19. Fisher, R.A. The use of multiple measurements in taxonomic problems. Ann. Eugenic. 1936, 7, $179-188$.

20. Moshou, D.; Bravo, C.; West, J.; Wahlen, S.; McCartney, A.; Ramon, H. Automatic detection of "yellow rust" in wheat using reflectance measurements and neural networks. Comput. Electron. Agr. 2004, 44, 173-188.

21. Rumpf, T.; Mahlein, A.-K.; Steiner, U.; Oerke, E.-C.; Plümer, L. Early detection and classification of plant diseases with support vector machines based on hyperspectral reflectance. Comput. Electron. Agric. 2010, 74, 91-99.

22. Camps-Valls, G.; Gomez-Chova, L.; Calpe-Maravilla, J.; Martin-Guerrero, J.D.; Soria-Olivas, E.; Alonso-Chorda, L.; Moreno, J. Robust support vector method for hyperspectral data classification and knowledge discovery. IEEE Trans. Geosci. Remote Sens. 2004, 42, 1530-1542.

23. Zanaty, E.A. Support Vector Machines (SVMs) versus Multilayer Perception (MLP) in data classification. Egypt Inform. J. 2012, 13, 177-183.

24. Vapnik, V. Statistical Learning Theory; Wiley-Interscience: New York, NY, USA, 1998.

25. De León, A.; Arriba, A.; De La Plaza, M.C. Caracterización Agroclimática de la Provincia de SEVILLA; Ministerio de Agricultura, Pesca y Alimentación: Madrid, Spain, 1989.

26. Mercado-Blanco, J.; Rodríguez-Jurado, D.; Parrilla-Araujo, S.; Jiménez-Díaz, R.M. Simultaneous detection of the defoliating and nondefoliating Verticillium dahliae pathotypes in infected olive plants by duplex, nested polymerase chain reaction. Plant Dis. 2003, 87, 1487-1494.

27. Zarco-Tejada, P.J.; González-Dugo, V.; Berni, J.A.J. Fluorescence, temperature and narrow-band indices acquired from a UAV for water stress detection using a hyperspectral imager and a thermal camera. Remote Sens. Environ. 2012, 117, 322-337.

28. Gueymard, C.A. SMARTS, A Simple Model of the Atmospheric Radiative Transfer of Sunshine: Algorithms and Performance Assessment; Technical report no. FSEC-PF-270-95; Florida Solar Energy Center: Cocoa, FL, USA, 1995.

29. Gueymard, C.A. Parameterized transmittance model for direct beam and circumsolar spectral irradiance. Sol. Energy 2001, 71, 325-346.

30. Berni, J.A.J.; Zarco-Tejada, P.J.; Sepulcre-Cantó, G.; Fereres, E.; Villalobos, F.J. Mapping canopy conductance and CWSI in olive orchards using high resolution thermal remote sensing imagery. Remote Sens. Environ. 2009a, 113, 2380-2388.

31. Berni, J.A.J.; Zarco-Tejada, P.J.; Suárez, L.; Fereres, E. Thermal and narrow-band multispectral remote sensing for vegetation monitoring from an unmanned aerial vehicle. IEEE Trans. Geosci. Remote Sens. 2009b, 47, 722-738.

32. Beisl, U. Correction of Bidirectional Effects in Imaging Spectrometer Data; Remote Sensing Series No. 37; Remote Sensing Laboratories: Zurich, Switzerland, 2001.

33. Rouse, J.W.; Haas, R.H.; Schell, J.A.; Deering, D.W.; Harlan, J.C. Monitoring the Vernal Advancement and Retrogradation (Greenwave Effect) of Natural Vegetation; NASA/GSFC Type III Final Report; College Station Texas A and M University: Greenbelt, MD, USA, 1974. 
34. Rougean, J.-L.; Breon, F.M. Estimating PAR absorbed by vegetation from bidirectional reflectance measurements. Remote Sens. Environ. 1995, 51, 375-384.

35. Liu, H.Q.; Huete, A.R. A feedback based modification of the NDVI to minimize canopy background and atmospheric noise. IEEE Trans. Geosci. Remote Sens. 1995, 33, 457-465.

36. Rondeaux, G.; Steven, M.; Baret, F. Optimization of soil-adjusted vegetation indices. Remote Sens. Environ. 1996, 55, 95-107.

37. Broge, N.H.; Leblanc, E. Comparing prediction power and stability of broadband and hyperspectral vegetation indices for estimation of green leaf area index and canopy chlorophyll density. Remote Sens. Environ. 2000, 76, 156-172.

38. Haboudane, D.; Miller, J.R.; Pattey, E.; Zarco-Tejada, P.J.; Strachan, I. Hyperspectral vegetation indices and novel algorithms for predicting green LAI of crop canopies: Modeling and validation in the context of precision agriculture. Remote Sens. Environ. 2004, 90, 337-352.

39. Chen, J. Evaluation of vegetation indices and modified simple ratio for boreal applications. Can. J. Remote Sens. 1996, 22, 229-242.

40. Gamon, J.A.; Peñuelas, J.; Field, C.B. A narrow-wave band spectral index that tracks diurnal changes in photosynthetic efficiency. Remote Sens. Environ. 1992, 41, 35-44.

41. Vogelmann, J.E.; Rock, B.N.; Moss, D.M. Red edge spectral measurements from sugar maple leaves. Int. J. Remote Sens. 1993, 14, 1563-1575.

42. Gitelson, A.A.; Merzlyak, M.N. Signature analysis of leaf reflectance spectra: Algorithm development for remote sensing of chlorophyll. Int. J. Remote Sens. 1997, 18, 2691-2697.

43. Blackburn, G.A. Spectral indices for estimating photosynthetic pigment concentrations: A test using senescent tree leaves. Int. J. Remote Sens. 1998, 19, 657-675.

44. Haboudane, D.; Miller, J.R.; Tremblay, N.; Zarco-Tejada, P.J.; Dextraze, L. Integrated narrow-band vegetation indices for prediction of crop chlorophyll content for application to precision agriculture. Remote Sens. Environ. 2002, 84, 416-426.

45. Gitelson, A.A.; Yacobi, Y.Z.; Schalles, J.F.; Rundquist, D.C.; Han, L.; Stark, R.; Etzion, D. Remote estimation of phytoplankton density in productive waters. Arch. Hydrobiol. 2000, 55, 121-136.

46. Zarco-Tejada, P.J.; Berjón, A.; López-Lozano, R.; Miller, J.R.; Marin, P.; Cachorro, V.; González, M.R.; de Frutos, A. Assessing vineyard condition with hyperspectral indices: Leaf and canopy reflectance simulation in a row-structured discontinuous canopy. Remote Sens. Environ. 2005, 99, 271-287.

47. Lichtenhaler, H.K.; Lang, M.; Sowinska, M.; Heisel, F.; Mieh, J.A. Detection of vegetation stress via a new high resolution fluorescence imaging system. J. Plant Physiol. 1996, 148, 599-612.

48. Plascyk, J.A. MK II Fraunhofer Line Dicsriminator (FLD-II) for airborne and orbital remote sensing of solar-stimulated luminescence. Opt. Eng. 1975, 14, 339-346.

49. Maier, S.W.; Günther, K.P.; Stellmes, M. Sun-induced fluorescence: A new tool for precision farming. In Digital Imaging and Spectral Techniques: Applications to Precision Agriculture and Crop Physiology; McDonald, M., Schepers, J., Tartly, L., van Toai, T., Major, D., Eds.; American Society of Agronomy: Madison, WI, USA, 2003; pp. 209-222. 
50. Mahlein, A.-K.; Rumpf, T.; Welke, P.; Dehne, H.-W.; Plümer, L.; Steiner., U.; Oerke, E.-C. Development of spectral indices for detecting and identifying plant diseases. Remote Sens. Environ. 2013, 128, 21-30.

51. Zarco-Tejada, P.J.; Catalina, A.; González, M.R.; Martín, P. Relationships between net photosynthesis and steady-state chlorophyll fluorescence retrieved from airborne hyperspectral imagery. Remote Sens. Environ. 2013, 136, 247-258.

52. National Institutes of Health, Bethesda, USA. Fiji Package of ImageJ Software. Available online: http://www.fiji.sc (accessed on 28 April 2015).

53. GRASS Development Team. GRASS GIS Software. Available online: http://grass.osgeo.org/ (accessed on 28 April 2015).

54. Khattree, R.; Naik, D.N. Multivariate Data Reduction and Discrimination with SAS Software; SAS Institute Inc.: Cary, NC, USA, 2000.

55. $\mathrm{R}$ Foundation for Statistical Computing. $\mathrm{R}$ Software, Version 3.1.1. Available online: http://www.R-project.org/ (accessed on 28 April 2015).

56. Meyer, D.; Dimitriadou, E.; Hornik, K.; Weingessel, A.; Leisch, F.; Chang, C.C.; Lin, C.C. Misc Functions of the Department of Statistics (e1071), TU Wien. R Package Version 1.6-4. Available online: http://rpackages.ianhowson.com/cran/e1071/ (accessed on 1 September 2014).

57. Chang, C.C.; Lin, C.J. LIBSVM: A Library for Support Vector Machines. Available online: http://www.csie.ntu.edu.tw/ cjlin/libsvm/ (accessed on 17 December 2014).

58. Huang, C.; Davis, L.S.; Townshend, J.R.G. An assessment of support vector machines for land cover classification. Int. J. Remote Sens. 2002, 23, 725-749.

59. Joachims, T. Text categorization with support vector machines: learning with many relevant features. In Machine Learning: ECML 1998; Nédellec, C., Rouveirol, C., Eds.; Springer: Heidelberg, Germany, 1998; Volume 1398, pp. 137-142.

60. Hsu, C.W.; Chang, C.C.; Lin, C.J. A practical guide to support vector classification. Available online: http://www.csie.ntu.edu.tw/ cjlin/papers/guide/guide.pdf (accessed on 17 December 2014).

61. Tjamos, E.C. Prospects and strategies in controlling Verticillium wilt of olive. Bull. OEPP/EPPO Bull. 1993, 23, 505-512.

62. Chang, C.-I. Data Dimensionality Reduction, in Hyperspectral Data Processing: Algorithm Design and Analysis; John Wiley \& Sons, Inc.: Hoboken, NJ, USA, 2013.

63. Zarco-Tejada, P.J.; Miller, J.R.; Mohammed, G.H.; Notlamd, T.L.L.; Sampson, P.H. Scaling-up and model inversion methods with narrow-band optical indices for chlorophyll content estimation in closed forest canopies with hyperspectral data. IEEE Trans. Geosci. Remote Sens. 2001, 39 , 1491-1507.

64. Laudien, R.; Bareth, G.; Doluschitz, R. Analysis of hyperspectral field data for detection of sugar beet diseases. In Proceedings of the EFITA Conference, Debrecen, Hungary, 5-9 July 2003; pp. 375-381.

65. Peñuelas, J.; Baret, F.; Filella, I. Semi-empirical indices to assess carotenoids/chlorophyll a ratio from leaf spectral reflectance. Photosynthetica 1995, 31, 221-230.

66. Hernández-Clemente, R.; Navarro-Cerrillo, R.M.; Suárez, L.; Morales, F.; Zarco-Tejada, P.J. Assessing structural effects on PRI for stress detection in conifer forests. Remote Sens. Environ. 2011, 115, 2360-2375. 
67. Naidu, R.A.; Perry, E.M.; Pierce, F.J.; Mekuria, T. The potential of spectral reflectance technique for the detection of Grapevine leafroll-associated virus-3 in two red-berried wine grape cultivars. Comput. Electron. Agr. 2009, 66, 38-45.

68. Römer, C.; Bürling, K.; Hunsche, M.; Rumpf, T.; Noga, G.; Plümer, L. Robust fitting of fluorescence spectra for pre-symptomatic wheat leaf rust detection with Support Vector Machines. Comput. Electron. Agr. 2011, 79, 180-188.

69. Nilsson, H.E. Remote sensing and image analysis in plant pathology. Annu. Rev. Phytopathol. 1995, 15, 489-527.

70. Chen, B.; Li, S.K.; Wang, K.R.; Wang, J.; Wang, F.Y.; Xiao, C.-H.; Lai, J.-C.; Wang, N. Spectrum characteristics of cotton canopy infected with Verticillium wilt and applications. Agric. Sci. China 2008, 7, 561-569.

71. Chen, B.; Li, S.; Wang, K.; Zhou, G.; Bai, J. Evaluating the severity level of cotton Verticillium using spectral signature analysis. Int. J. Remote Sens. 2011, 33, 2706-2724.

(C) 2015 by the authors; licensee MDPI, Basel, Switzerland. This article is an open access article distributed under the terms and conditions of the Creative Commons Attribution license (http://creativecommons.org/licenses/by/4.0/). 